\title{
Article \\ Multi-Drug Resistant Escherichia coli, Biosecurity and Anti-Microbial Use in Live Bird Markets, Abeokuta, Nigeria
}

Oluwawemimo Adebowale ${ }^{1, *}$, Motunrayo Makanjuola ${ }^{1}$, Noah Bankole ${ }^{2}$, Mary Olasoju ${ }^{1} \mathbb{D}$, Aderonke Alamu $^{3}$, Eniola Kperegbeyi ${ }^{1}$, Oladotun Oladejo ${ }^{1}$, Olubunmi Fasanmi ${ }^{4}\left(\mathbb{D}\right.$, Olanike Adeyemo ${ }^{5}$ and Folorunso O. Fasina ${ }^{6,7} \mathbb{C}$

1 Department of Veterinary Public Health and Preventive Medicine, College of Veterinary Medicine, Federal University of Agriculture, Abeokuta 110124, Nigeria; makanjuolamotunrayo21@gmail.com (M.M.); maryvet2006@yahoo.com (M.O.); eny2be.ek@gmail.com (E.K.); oladejodotun@gmail.com (O.O.)

2 Department of Veterinary Microbiology, College of Veterinary Medicine, Federal University of Agriculture, Abeokuta 110124, Nigeria; noahbankole95@gmail.com

3 Department of Veterinary Medicine, College of Veterinary Medicine, Federal University of Agriculture, Abeokuta 110124, Nigeria; aderonkemi493@gmail.com

4 Department of Veterinary Laboratory Technology, Federal College of Animal Health and Production Technology, Ibadan 200262, Nigeria; bumaetal@gmail.com

5 Department of Veterinary Public Health and Preventive Medicine, University of Ibadan, Ibadan 200284, Nigeria; olanikeadeyemo@hotmail.com

6 ECTAD, Food and Agriculture Organization of the United Nations (FAO), Dar es Salaam 14111, Tanzania; daydupe2003@yahoo.co.uk

7 Department of Veterinary Tropical Diseases, University of Pretoria, Pretoria 0110, South Africa

* Correspondence: adebowaleoluwawemimo1@gmail.com; Tel.: +234-(0)-90-8560-8043

Citation: Adebowale, $\mathrm{O}$.

Makanjuola, M.; Bankole, N.; Olasoju,

M.; Alamu, A.; Kperegbeyi, E.;

Oladejo, O.; Fasanmi, O.; Adeyemo,

O.; Fasina, F.O. Multi-Drug Resistant

Escherichia coli, Biosecurity and

Anti-Microbial Use in Live Bird

Markets, Abeokuta, Nigeria.

Antibiotics 2022, 11, 253. https://

doi.org/10.3390/antibiotics11020253

Academic Editors: David Rodríguez-

Lázaro and María Ugarte Ruiz

Received: 31 December 2021

Accepted: 9 February 2022

Published: 16 February 2022

Publisher's Note: MDPI stays neutral with regard to jurisdictional claims in published maps and institutional affiliations.

Copyright: (C) 2022 by the authors. Licensee MDPI, Basel, Switzerland. This article is an open access article distributed under the terms and conditions of the Creative Commons Attribution (CC BY) license (https:// creativecommons.org/licenses/by/ $4.0 /)$.

\begin{abstract}
Live bird markets (LBM) remain a critical link from farm to fork in the poultry value chain, which oftentimes promotes indiscriminate antimicrobial use (AMU) and resistance (AMR). In this study, we assessed biosecurity practices, AMU, and associated these with multidrug resistant (MDR) E. coli in LBMs in Abeokuta, Ogun State. A cross-sectional survey among live bird sellers (LBS) in eight LBMs was conducted using a semi-structured questionnaire. Also, cloacal samples $(n=200)$ were randomly collected and pooled for bacteriological detection of MDR E. coli in live chickens of consenting LBS. Susceptibility to 14 antimicrobials belonging to 6 different classes was determined using the disk diffusion method. Biosecurity level and AMU were generally low. LBS less than 46 (Crudes odds ratio $=6.8 ; 95 \%$ CI; $1.20-38.56 ; p=0.03$ ) than others. An informal or primary school education increased the odds of having a poor practice of AMU by 15.1 folds (Crudes odds ratio $=15.1 ; 95 \% \mathrm{CI} ; 2.73-84.18 ; p=0.002$ ) than those with secondary or tertiary. The prevalence of E. coli and MDR E. coli at the LBM level were $80 \%$ and 56.3\%, respectively. Extremely high resistance rates were observed for ceftazidime (96.9\%) and imipenem (90.6\%). The odds of MDR E. coli increased eight-fold in poultry kept by LBS who use AMs as prophylaxis. This current data could be useful for the development of targeted behavioral risk communication and mitigation strategies for AMR to impede the potential horizontal transfer of AMR genes to humans through animal-sourced food.
\end{abstract}

Keywords: antibiotics; antimicrobial stewardship program; multidrug resistant Escherichia coli; live bird market; Nigeria

\section{Introduction}

In the Nigerian' poultry value chain, live bird markets (LBMs) are essential to the farmers for the preferential sales and marketing of poultry and poultry products for human consumption [1]. The LBMs are typically in urban, peri-urban, and rural settings and typified by permanently placed pen-like structures in which the chickens can be temporarily housed until they are sold [2]. The LBMs bring together a variety of multi-farmed, multisourced, and multi-aged poultry species to meet the preferences of various customers [3]. 
Poultry traders and middlemen have many trade links with farms, roads, abattoirs, slaughter slabs, households, and many other locations, which have been associated with the dissemination of poultry diseases of public health importance and the persistent pool of antimicrobial multidrug-resistant bacteria pathogens $[4,5]$. Poor biosecurity measures in LBMs in Nigeria could create conditions that promote the spread of diseases and resistant bacterial strains [4,6]. One such common bacterial pathogen is Escherichia coli [7]. Many families in Nigeria depend on the consumption of poultry products such as egg and meat as protein sources, and therefore their risk of exposure to these pathogens and resistant strains potentially increase.

Escherichia coli are Gram-negative bacteria of the Enterobacteriales. These multi-strain organisms are widely distributed in nature, being present in soil and surface water and animal and human feces [8]. The bacteria include not only commensal strains but also pathogenic ones that cause a variety of human and animal diseases resulting directly or indirectly in more than 2 million deaths each year [9]. Pathogenic E. coli strains are implicated in many water and foodborne disease outbreaks worldwide, especially Shiga toxin Escherichia coli (STEC) and enteropathogenic Escherichia coli (EPEC) [10]. Since E. coli commonly reside in the intestines of warm-blooded animals, it is subjected to frequent encounters with antimicrobials and provides it with high selection pressure leading to a high likelihood of resistance against multiple antimicrobials consumed by its host [11]. There is the major concern of possible transmission of virulent and/or resistant $E$. coli between animals and humans through numerous pathways, such as direct contact and contact with animal excretions, through the environment, or via the food chain [8].

Antimicrobial resistance (AMR) is a major global health threat as multidrug-resistant (MDR) organisms are increasing mortality and economic burden in humans and livestock animals. Nigeria is no exception to this challenge [5]. The most common risk practice by farmers that may contribute to the emergence, selection, and dissemination of AMR microorganisms in poultry has been linked to indiscriminate antimicrobial usage (AMU) [12-14]. Commonly used antibiotics in poultry production in Nigeria include oxytetracycline, neomycin, enrofloxacin, doxycycline, gentamicin, colistin, streptomycin, tylosin, ciprofloxacin, nitrofurans, furazolidone, and chloramphenicol [5,12]. Several of these antimicrobials are misused and administered prophylactically either in drinking water or incorporated in poultry feeds [13,15]. Reasons for the indiscriminate use of antimicrobials in the poultry production chain were adduced as follows: (1) farmers' efforts to reduce the burden of diseases on poultry health, (2) growth promotion in food animals to increase feed-to-muscle conversion rate and profits, (3) inaccessible and expensive veterinary services, (4) weak or non-existing antibiotic policies in the country, and (5) poor farm management or biosecurity practices $[7,13,16]$.

AMR E. coli are commonly found in food producing animals such as in the gastrointestinal tract of chickens and facilities in which these chickens are housed [17-19]. The presence and persistence of resistance in commensal $E$. coli is a significant biomarker for the selective pressure enforced by antibiotic use and subsequent resistance predicted in other potentially pathogenic bacteria [20]. The high prevalence of MDR E. coli in poultry has been evaluated and reported in several countries including Nigeria [5,21-25]. However, only a few studies on MDR E. coli among chickens in LBMs in the country exist. Furthermore, to the best of our knowledge, risk factors predisposing to antimicrobial use and the consequent development of MDR E. coli in LBMs in Ogun State are yet to be documented. Hence, this study focused on factors associated with AMU and MDR E. coli in live bird markets and the potential public health implications within Abeokuta city, Ogun State, Nigeria.

\section{Results}

2.1. Participating Live Bird Sellers (LBS) and Live Bird Markets (LBMs) Characteristics

A total of 40 LBS out of the 80 eligible participated in the study $($ response rate $(R R)=$ $50 \%$ ). Figure 1 represents the flow chart process for recruitment and sample collection. 


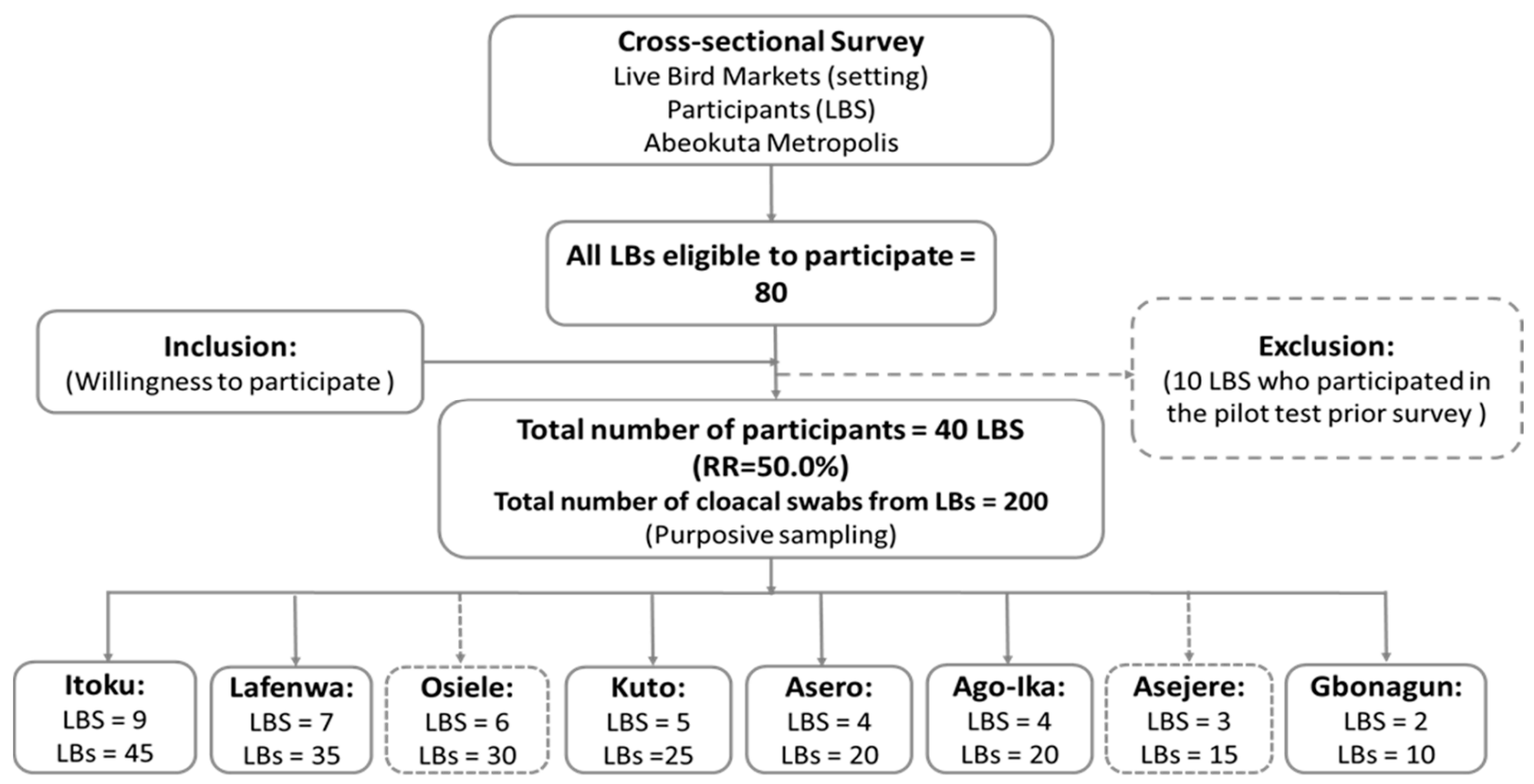

Figure 1. Summary study flowchart indicating the outcome of respondents' recruitment process and sample collection.

All of the LBMs visited were within the Ogun Central district, one of the three senatorial districts in Ogun state. LBM capacity varied between a few hundred to several thousand chickens and the number of sellers ranged from approximately five to fifteen. The seven Abeokuta LBMs open from 7:00 am to 7:30 pm from Monday to Saturday. However, some LBS at Kuto and Lafenwa LBMs operate on Sundays.

The various types and total number of poultry present included laying hens (875, median 25), broilers (515, median 25), cockerels (380, median 20), ducks (40, median 20) and others such as pigeon and local chickens (405, median 25). Six (75.0\%) of the eight LBMs visited had mixed poultry of various age groups and types. Poultry were majorly housed in metal cages $22(55.0 \%)$. Other forms of housing were wooden $(14(35.0 \%))$ or raffia based $(4(10.0 \%))$. The median distance between cages was estimated at $22.5 \mathrm{~cm}$ (Minimum $=10$, Maximum $=150$ ).

In all of the LBMs, poultry were fed mainly commercial feeds. Major sources of water supply described and available to respondents were boreholes (77.5\%) and well (dug well) (75.0\%) respectively. All LBMs had no electricity supply, no slaughtering and processing facilities despite being established mainly for selling and slaughtering live chickens.

Live birds (LBs) were sourced from various farms and locations within and outside Abeokuta, Ogun state. These sources and distances to Abeokuta central included but were not limited to: Mile $6(\approx 10 \mathrm{~km})$, Ijebu $(\approx 87 \mathrm{~km})$, Yewa $(\approx 8 \mathrm{~km})$, Shagamu $(\approx 54 \mathrm{~km})$, and Remo $(\approx 63 \mathrm{~km})$. In addition, six LBMs $(75.0 \%)$ get poultry supplies from contiguous states such as Oyo and Lagos, but none from neighboring countries. Seven of the LBMs (87.7\%) were not fenced and were sited in residential areas (approximately 100 meters to $5 / 7$ of the LBMs). The presence of wild chickens was also observed in the premises of $50 \%$ of the LBMs (Figure 2). Other animal types present in proximity with LBs were goats, sheep, and cattle. Dogs, cats, and rats were observed at one of the LBM during the visits (Itoku).

\subsection{Live Bird Sellers Demographics}

Out of the 40 LBS who participated in the study, $85.0 \%$ were females and $15.0 \%$ were males. The respondents' mean age was 46 years, $(\mathrm{SD} \pm 11)$ and the mean years as LBS was $21(\mathrm{SD} \pm 11)$. The mean number of work hour per day was $10 \mathrm{~h}(\mathrm{SD} \pm 0.4)$, and the majority $(85.0 \%)$ worked seven days a week. Most of the respondents were married $(92.3 \%)$ and $45 \%$ 
declared that they have no formal education. None of the LBS specified their income per week (Table 1).

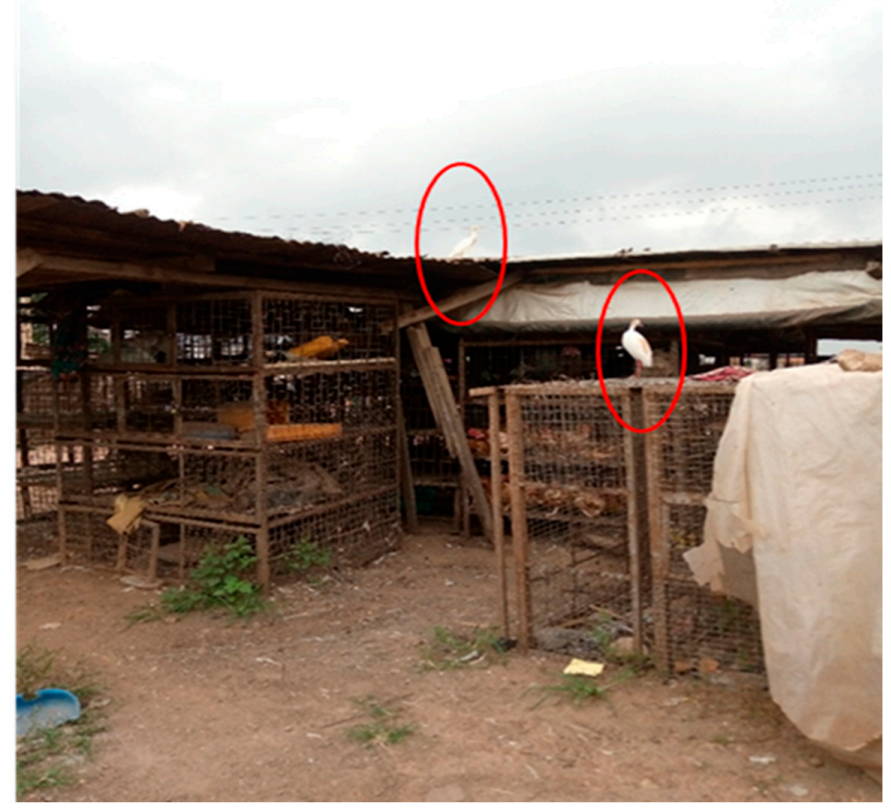

Figure 2. Migratory wild chickens were observed to be perching on cages close to the caged live chickens.

Table 1. Sociodemographic profiles of respondents (LBS) from the eight LBMs investigated in Abeokuta, Ogun State.

\begin{tabular}{|c|c|c|c|}
\hline Variables & Frequency & Percent $(\%)$ & $95 \% \mathrm{CI}$ \\
\hline \multicolumn{4}{|c|}{ Gender $(n=40)$} \\
\hline Male & 6 & 15.0 & $6.7-29.5$ \\
\hline Female & 34 & 85.0 & $70.5-93.3$ \\
\hline \multicolumn{4}{|c|}{ Marital Status $(n=39)$} \\
\hline Single & 3 & 7.7 & $1.9-21.0$ \\
\hline Married & 36 & 92.3 & $79.0-98.1$ \\
\hline \multicolumn{4}{|c|}{ Age (in years, $n=37$ ) } \\
\hline $20-30$ & 5 & 13.5 & $5.4-2.8$ \\
\hline $31-40$ & 9 & 24.3 & $13.2-40.3$ \\
\hline $41-50$ & 12 & 32.5 & $19.6-48.6$ \\
\hline $51-60$ & 8 & 21.6 & $11.1-37.4$ \\
\hline $61-70$ & 3 & 8.1 & $2.1-22.0$ \\
\hline \multicolumn{4}{|c|}{ Educational level $(n=39)$} \\
\hline Informal & 18 & 45.0 & $31.6-61.4$ \\
\hline Primary & 12 & 30.0 & $18.5-46.5$ \\
\hline Secondary & 9 & 22.5 & $12.4-38.5$ \\
\hline Tertiary & 1 & 2.5 & $<0.01-14.4$ \\
\hline \multicolumn{4}{|c|}{ Primary Occupation [live bird, $(n=40)]$} \\
\hline No & 3 & 7.5 & 1.9-20.6 \\
\hline Yes & 92.5 & 37 & $79.4-98.1$ \\
\hline \multicolumn{4}{|c|}{ Membership of the LBS Association $(n=40)$} \\
\hline No & $5^{1}$ & 12.5 & $5.0-26.6$ \\
\hline Yes & 35 & 87.5 & $73.4-95.0$ \\
\hline \multicolumn{4}{|c|}{ Contact with a Vet $(n=39)$} \\
\hline Yes & 23 & 59.0 & $43.4-72.9$ \\
\hline No & 16 & 41.0 & $27.1-56.6$ \\
\hline
\end{tabular}




\subsection{Biosecurity in the LBMs in Abeokuta, Ogun State}

Concerning biosecurity practices within the LBMs (Figure 3), respondents confirmed that chickens were sourced from different farms. Also, chickens of different species and ages were mixed. A total of $62.5 \%, 55.5 \%$, and $25.6 \%$ source poultry from different commercial farms, other LBS and middlemen, respectively. LBS $(80.0 \%)$ do not carry out health inspections of poultry on arrival from the various sources and $77.5 \%$ introduced chickens into the market without quarantine. Emergency slaughter and sale, especially of sick chickens, were carried out by over $77.5 \%$ of the respondents. The presence of sick poultry was observed in the stalls of over $45.0 \%$ LBS, while over $60.0 \%$ and $55.5 \%$ do not separate sick from healthy poultry and had overcrowded poultry, respectively. Main procedures for cleaning involved the use of soap and water (22.5\%), sweeping, dusting and scraping $(20.0 \%)$, and use of household phenols and water $(7.5 \%)$. The majority of the LBS dispose poultry waste in open dumps (70.0\%). Table 2 is the distribution of responses to biosecurity questions provided by LBS who participated in the study.

The biosecurity level among LBS was poor with a mean score of $41.8 \%$ (SD $11.6 \%$, total score 25$)$. In this study, $70.0 \%$ of the respondents fell within the poor biosecurity level $(<50.0 \%$, range $23.3-46.7 \%)$, while others $(30 \%)$ were satisfactory $(>50.0 \%$, range $60.0-66.7 \%)$. There was a weak positive correlation between the two variables, though not statistically significant $(r=0.23, n=40, p=0.15)$.

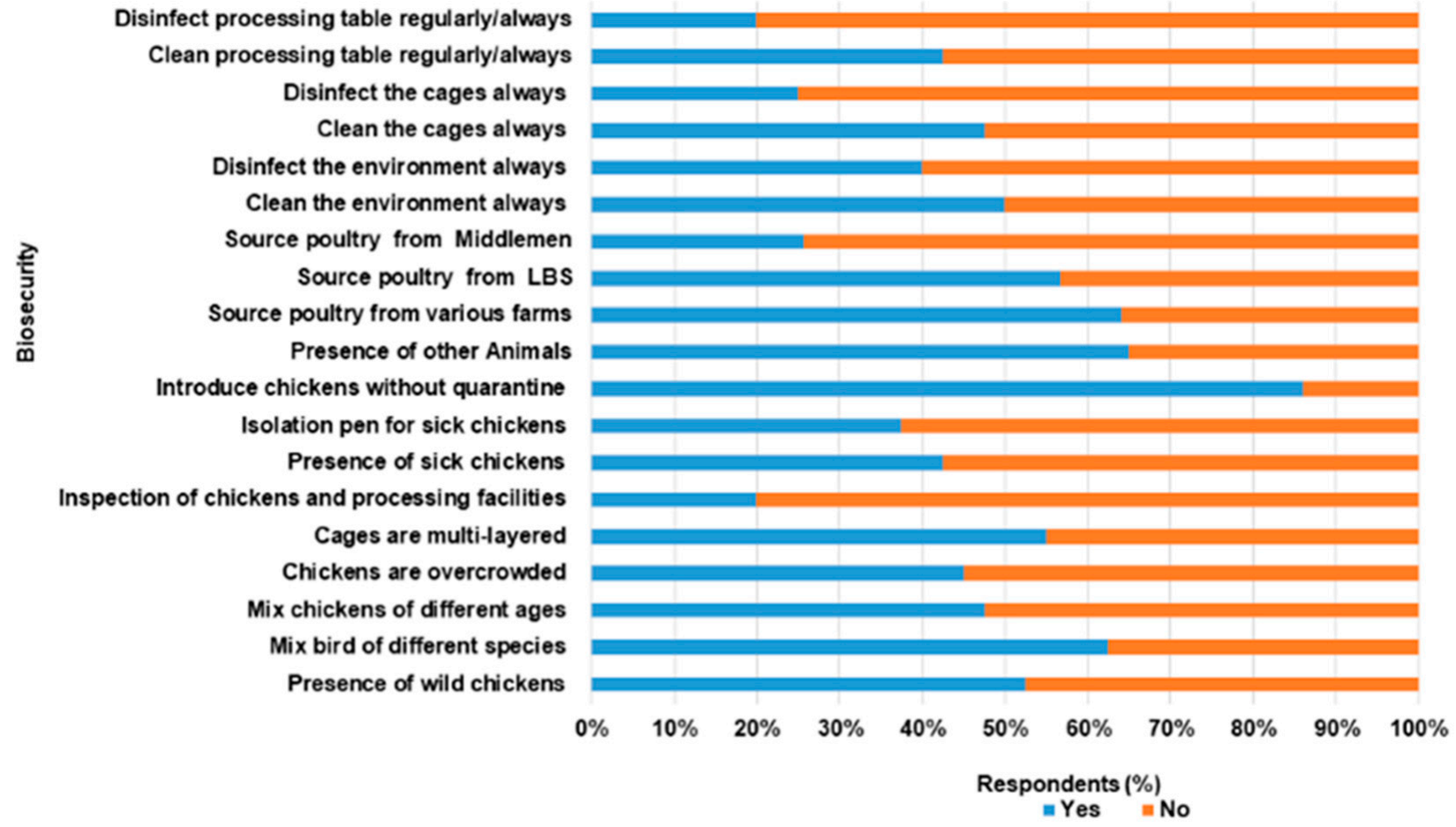

Figure 3. Biosecurity practices among Live bird Sellers in Abeokuta, Ogun State. 
Table 2. The distribution of responses to biosecurity and antimicrobial use question among LBS in Abeokuta, Ogun state $(n=40)$.

\begin{tabular}{|c|c|c|c|c|c|}
\hline Questions/Variables & Options & Score & Responses (n) & $(\%)$ & $95 \%$ CI \\
\hline \multicolumn{6}{|l|}{ Biosecurity } \\
\hline \multirow{2}{*}{ B1. Presence of wild chickens $(n=40)$} & Yes & 0 & 21 & 52.5 & $37.5-67.1$ \\
\hline & No & 1 & 19 & 47.5 & $32.9-62.5$ \\
\hline \multirow{2}{*}{ B2. Mix bird of different species $(n=40)$} & Yes & 0 & 25 & 62.5 & $47.0-75.8$ \\
\hline & No & 1 & 15 & 37.5 & $24.2-53.0$ \\
\hline \multirow{2}{*}{ B3. Mix chickens of different ages $(n=40)$} & Yes & 0 & 19 & 47.5 & $32.93-62.5$ \\
\hline & No & 1 & 21 & 52.5 & $37.5-67.1$ \\
\hline \multirow{2}{*}{ B4. Chickens are overcrowded $(n=40)$} & Yes & 0 & 18 & 45 & $30.7-60.2$ \\
\hline & No & 1 & 22 & 55 & $39.8-69.3$ \\
\hline \multirow{2}{*}{ B5. Cages are multi-layered $(n=40)$} & Yes & 0 & 22 & 55 & $39.8-69.3$ \\
\hline & No & 1 & 18 & 45 & $30.7-60.2$ \\
\hline \multirow{2}{*}{ B6. Inspection of chickens and processing facilities $(n=40)$} & Yes & 1 & 8 & 20 & $10.2-35.0$ \\
\hline & No & 0 & 32 & 80 & $65.0-89.8$ \\
\hline \multirow{2}{*}{ B7. Presence of sick chickens $(n=40)$} & Yes & 0 & 17 & 42.5 & $28.50-57.8$ \\
\hline & No & 1 & 23 & 57.5 & $42.2-71.5$ \\
\hline \multirow{2}{*}{ B8. Isolation pen for sick chickens $(n=40)$} & Yes & 1 & 15 & 37.5 & $24.2-53.0$ \\
\hline & No & 0 & 25 & 62.5 & $47.0-75.8$ \\
\hline \multirow{2}{*}{ B9. Introduce chickens without quarantine $(n=36)$} & Yes & 0 & 31 & 77.5 & $70.9-94.4$ \\
\hline & No & 1 & 5 & 12.5 & $5.6-29.1$ \\
\hline \multirow{2}{*}{ B10. Presence of other Animals $(n=40)$} & Yes & 0 & 26 & 65 & $49.5-77.9$ \\
\hline & No & 1 & 14 & 35 & $22.1-50.6$ \\
\hline \multirow{9}{*}{ B11. Source of Poultry $(n=39)$} & \multicolumn{5}{|c|}{ Various farms } \\
\hline & Yes & 0 & 25 & 62.5 & $49.5-77.9$ \\
\hline & No & 1 & 14 & 35 & $22.1-50.6$ \\
\hline & \multicolumn{5}{|c|}{ Various LBS } \\
\hline & Yes & 0 & 22 & 55.5 & $41.0-70.7$ \\
\hline & No & 1 & 17 & 42.5 & $29.3-59.0$ \\
\hline & \multicolumn{5}{|c|}{ Various Middlemen $(\mathrm{n}=39)$} \\
\hline & Yes & 0 & 10 & 25.6 & $14.4-41.2$ \\
\hline & No & 1 & 29 & 74.4 & $58.8-85.6$ \\
\hline & Metal & 1 & 22 & 55 & $39.8-69.3$ \\
\hline B12. Cage Type $(n=40)$ & $\begin{array}{l}\text { Non- } \\
\text { metal }\end{array}$ & 0 & 18 & 45 & $30.7-60.2$ \\
\hline \multirow{2}{*}{ B13. Clean the environment always $(n=40)$} & Yes & 1 & 20 & 50 & $35.2-64.8$ \\
\hline & No & 0 & 20 & 50 & $35.2-64.8$ \\
\hline \multirow{2}{*}{ B14. Disinfect the environment always $(n=40)$} & Yes & 1 & 16 & 40 & $26.3-55.4$ \\
\hline & No & 0 & 24 & 60 & $44.6-73.7$ \\
\hline \multirow{2}{*}{ B15. Clean the cages always $(n=40)$} & Yes & 1 & 19 & 47.5 & $32.9-62.5$ \\
\hline & No & 0 & 21 & 52.5 & $37.5-67.1$ \\
\hline
\end{tabular}


Table 2. Cont.

\begin{tabular}{ccccccc}
\hline Questions/Variables & Options & Score & Responses (n) & (\%) & 95\% CI \\
\hline B16. Disinfect the cages always $(n=40)$ & Yes & 1 & 10 & 25 & $14.0-40.4$ \\
\cline { 2 - 6 } & No & 0 & 30 & 75 & $59.6-86.0$ \\
\hline \multirow{2}{*}{ B17. Clean processing table regularly/always $(n=40)$} & Yes & 1 & 17 & 42.5 & $28.5-57.8$ \\
\cline { 2 - 6 } & No & 0 & 23 & 57.5 & $42.2-71.5$ \\
\hline \multirow{2}{*}{ B18. Disinfect processing table regularly/always $(n=40)$} & Yes & 1 & 8 & 20 & $10.2-35.0$ \\
\cline { 2 - 6 } & No & 0 & 32 & 80 & $65.0-89.8$ \\
\hline
\end{tabular}

\section{Antimicrobial use}

A1. Aware of antimicrobials $(n=40)$

\begin{tabular}{ccccc} 
Yes & 1 & 40 & 100 & $89.6-1.0$ \\
\hline No & 0 & 0 & 0 & $0.0-10.4$ \\
\hline Yes & 0 & 35 & 87.5 & $76.4-96.6$ \\
\hline No & 1 & 5 & 12.5 & $3.4-23.6$
\end{tabular}

A2. Use Antimicrobials for poultry? $(n=40)$

\begin{tabular}{ccccc}
\multicolumn{5}{c}{ Treat diseases } \\
\hline Yes & 1 & 20 & 50 & $35.2-64.8$ \\
\hline No & 0 & 20 & 50 & $35.2-64.8$ \\
\hline \multicolumn{5}{c}{ Prevent diseases } \\
\hline Yes & 0 & 21 & 52.5 & $37.50-67.1$ \\
\hline No & 1 & 19 & 47.5 & $32.9-62.5$
\end{tabular}

A3. For what purpose? $(n=40)$

A4. How do you administer drugs? $(n=40)$

A5. Where do you obtain antimicrobials for your chickens? $(n=40)$

Call a veterinarian

\begin{tabular}{ccccc}
\hline Yes & 1 & 4 & 10 & $3.4-23.6$ \\
\hline No & 0 & 36 & 90 & $76.4-96.6$ \\
\hline Self & \multicolumn{3}{c}{} \\
\hline Yes & 0 & 36 & 90 & $76.4-96.6$ \\
\hline No & 1 & 4 & 10 & $3.4-23.6$ \\
\hline Yes & 1 & Vet Shops & \\
\hline No & 0 & 22 & 55 & $39.8-69.3$ \\
\hline & & 18 & 45 & $30.7-60.2$ \\
\hline
\end{tabular}

Pharmacy shops

\begin{tabular}{ccccc}
\hline Yes & 0 & 29 & 72.5 & $57.0-84.0$ \\
\hline No & 1 & 11 & 27.5 & $16.0-43.0$ \\
\hline \multicolumn{5}{c}{ Poultry farmers } \\
\hline Yes & 0 & 10 & 25 & $14.0-40.4$ \\
\hline No & 1 & 30 & 75 & $59.6-86.0$ \\
\hline
\end{tabular}

Live Bird Sellers

\begin{tabular}{|c|c|c|c|c|c|}
\hline & Yes & 0 & 11 & 27.5 & $16.0-43.0$ \\
\hline & No & 1 & 29 & 72.5 & $57.0-84.0$ \\
\hline \multirow{2}{*}{$\begin{array}{l}\text { A6. Are you influenced by company's brand before use? } \\
\qquad(n=40)\end{array}$} & Yes & 0 & 24 & 60 & 44.673 .7 \\
\hline & No & 1 & 16 & 40 & $26.3-55.4$ \\
\hline
\end{tabular}

\subsection{Antimicrobial Use among LBS in LBMs in Abeokuta, Ogun State}

Table 2 above described the responses of respondents to questions asked on AMU. In this survey, $87.5 \%$ of the respondents use antimicrobials in chickens. Out of all of the LBS, $55.0 \%$ and $20.0 \%$ use antimicrobials for therapeutics and prophylaxis purposes 
respectively. Figure 4 describes AMU among LBS respondents in Abeokuta. Generally, tetracycline, metronidazole and chloramphenicol were commonly used AMs by LBS in Abeokuta (Figure 5a). Figure 5b shows the distribution of AMs used among LBS across the various LBMs.

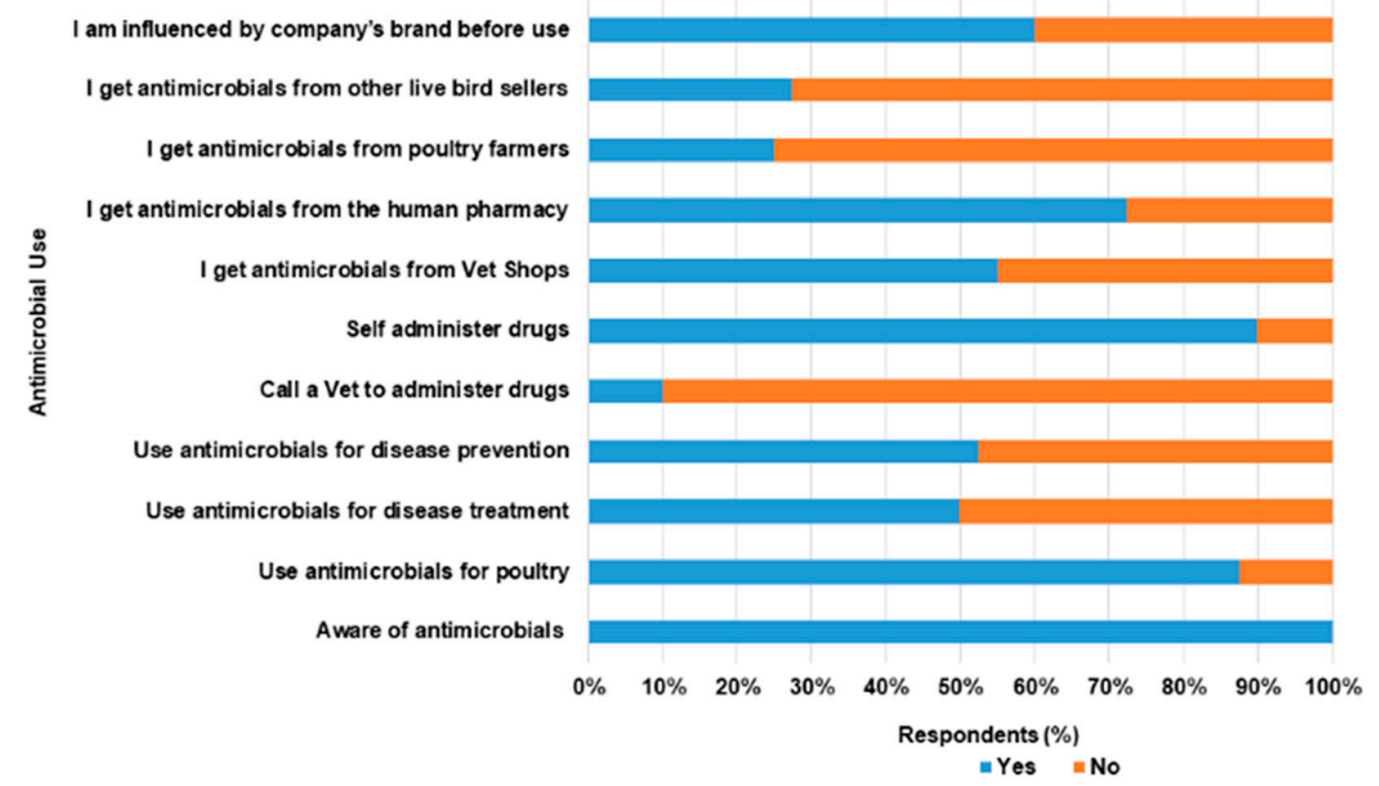

Figure 4. Antimicrobial use among live bird sellers in Abeokuta, Ogun State.

a

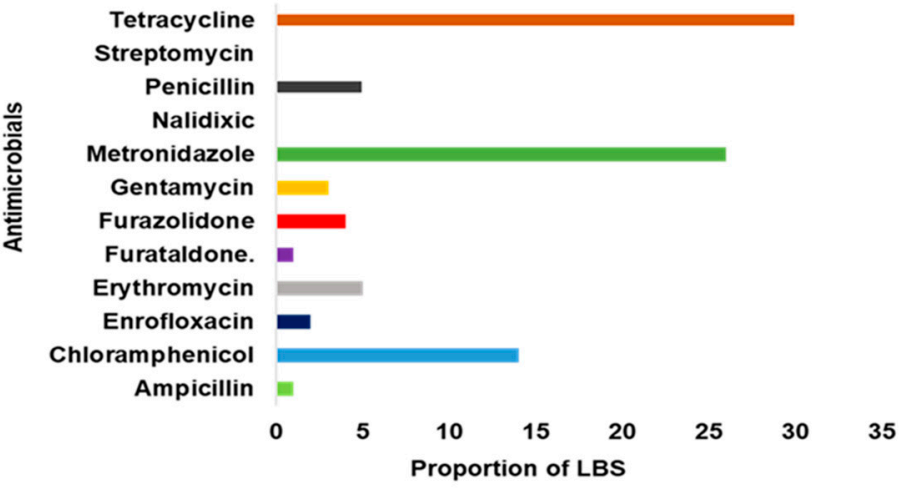

b

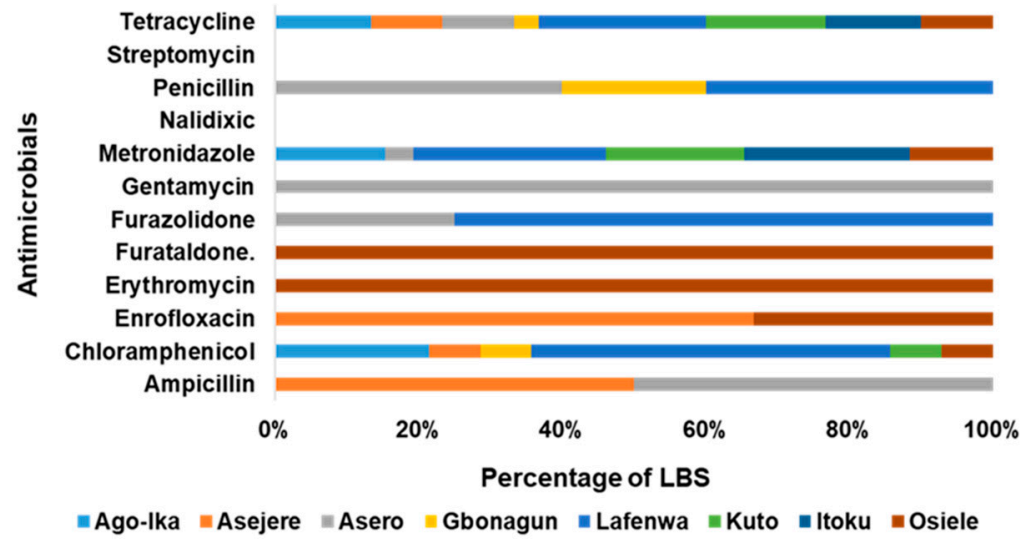

Figure 5. (a) Most commonly used AMs among LBS in Abeokuta, Ogun State. (b) The distribution of common antimicrobials (AMs) used across LBMs in Abeokuta, Ogun State.

On how sick poultry were treated, only $12.5 \%$ made use of veterinary services, while the majority self-administered treatment $(80.0 \%)$ and others $(7.5 \%)$ patronize other live 
bird sellers. Common sources of purchase of antimicrobials were veterinary outlets (55.0\%) and human pharmacies (27.5\%). Respondents claimed that the use of AMs was influenced majorly by previous experiences $(62.5 \%)$ and least by veterinarians $(5.0 \%)$. Encapsulated antimicrobials targeted at humans have been used by $67.5 \%$ of the participant for treatment of diseases in poultry. A few of the human AMs used were tetracycline, metronidazole and chloramphenicol. No withdrawal period was observed by respondents $(95.0 \%)$ while $100.0 \%$ were unaware of AMR. Within the period of our visits, $12.5 \%$ of the respondents still administered antimicrobials such as tetracycline, oxytetracycline, and colistin to poultry. Of these numbers, $10.0 \%$ of the respondents self- reported to have slaughtered and sold poultry to consumers within 24-48 h of treatment.

Generally, the mean score for the practice of Antimicrobial Use (AMU) was 37.5\% (SD $13.1 \%$, Total score 30$)$. A total of 29 respondents $(72.5 \%)$ had poor practice of AMU $(<50 \%$, $12.5-45.8 \%)$, while 11 (27.5\%) displayed satisfactory level (50.0-66.7\%). The respondents' preferred sources of information on Antimicrobial Stewardship Program (AMSP) in ascending order were veterinary extension services $(5.0 \%)$, mass media $(22.5 \%$ television and $42.5 \%$ radio) and seminars $(92.5 \%)$.

Only age was the sociodemographic variable of the LBS found to be associated with poor biosecurity level. LBS below the age of 46 years had 6.8 higher odds of having poor biosecurity level (COR $=6.8 ; 95 \% \mathrm{CI} ; 1.20-38.56 ; p=0.03)$ than others. Similarly, an informal or primary school educational background increased the odds of having poor AMU by 15.1 times $(\mathrm{COR}=15.1 ; 95 \% \mathrm{CI} ; 2.73-84.18 ; p=0.002)$ than secondary or tertiary (Table 3$)$.

Table 3. Sociodemographic information of LBS associated with biosecurity and AMU using bivariate analysis.

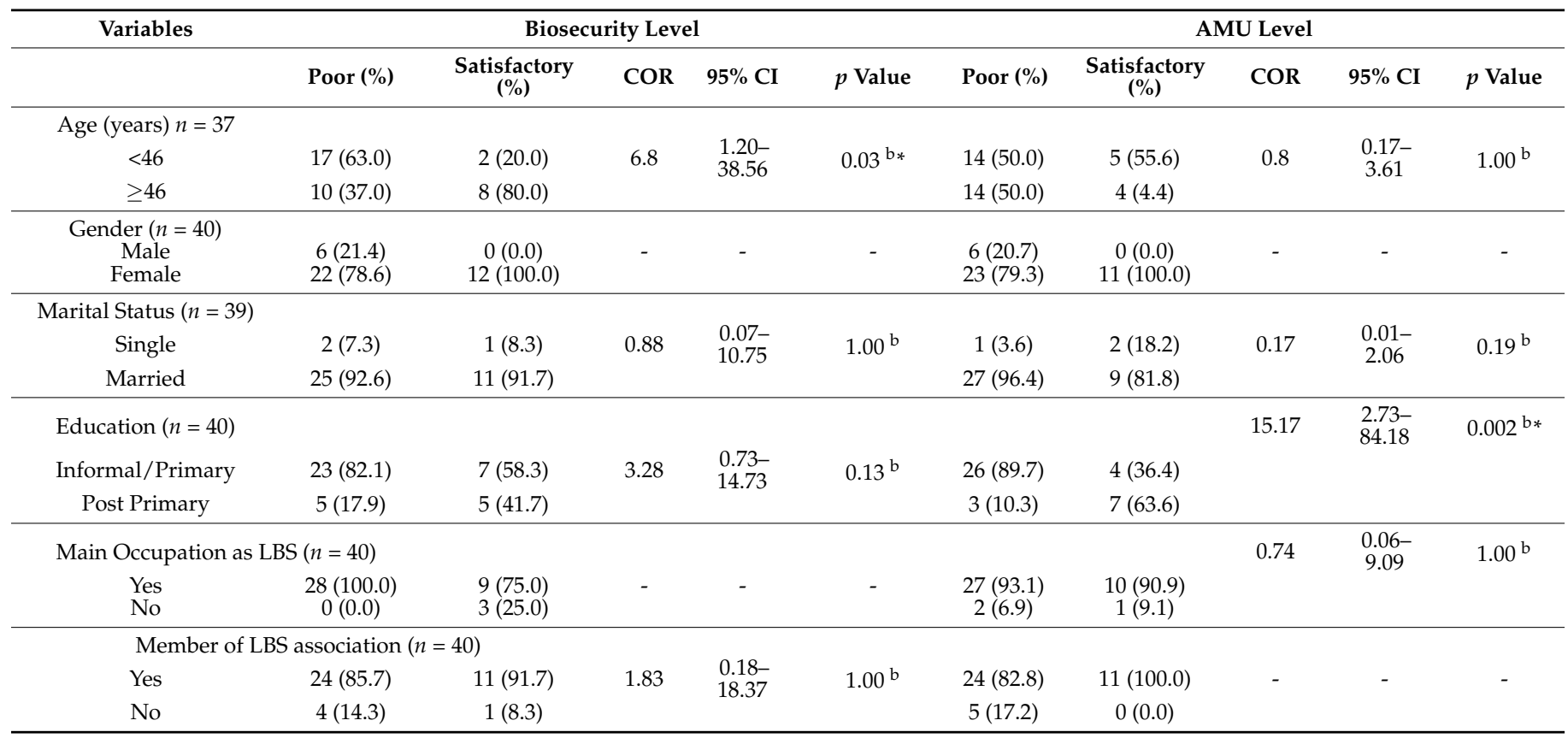

* Significant at $p \leq 0.05 ;{ }^{\mathrm{b}}=$ Fischer's exact test; COR, Crude's odds ratio; CI, confidence interval.

\subsection{Prevalence of E. coli and the Multidrug Resistance Profile in Live Birds (LBs) in Abeokuta city, Ogun State}

The overall prevalence of $E$. coli positive samples after pooling was $80.0 \%(32 / 40 ; 95 \%$ CI, 64.9-89.7\%). MDR was estimated in 56.3\% (95\% CI, 39.3-71.8\%) of all putative positive E. coli isolates (Table 4). The other positive isolates were non-MDR (43.7\%). The highest numbers of E. coli $(28.1 \%, 95 \%$ CI, $15.4-45.5 \%)$ and MDR E. coli $(33.3 \%, 95 \%$ CI, $16.1-56.4 \%)$ were isolated from Itoku LBM. Table 5 presents the multiple antibiotic resistance Index (MARI) estimated as 0.27 for all of the MDR isolates (ranging from 0.2 to 0.5 ). 
Table 4. Distribution of E. coli and multidrug resistance.

\begin{tabular}{ccccc}
\hline LBM & $\begin{array}{c}\text { E. coli Positive } \\
\text { Samples }(\boldsymbol{n = 3 2 )}\end{array}$ & $\begin{array}{c}\text { Prevalence of } \\
\text { E.coli Isolates } \\
\mathbf{( \% )}\end{array}$ & $\begin{array}{c}\text { MDR E. coli } \\
\text { Positive } \\
\text { Samples }(\boldsymbol{n}=\mathbf{1 8})\end{array}$ & $\begin{array}{c}\text { Prevalence of } \\
\text { MDR } \text { E. coli(\%) }\end{array}$ \\
\hline Lafenwa & 3 & 9.4 & - & 0.0 \\
Kuto & 4 & 12.5 & 2 & 11.1 \\
Itoku & 9 & 28.1 & 6 & 33.3 \\
Gbonagun & 1 & 3.1 & 1 & 5.6 \\
Ago ika & 3 & 9.4 & 2 & 11.1 \\
Asero & 4 & 12.5 & 2 & 11.1 \\
Asejere & 3 & 9.4 & 2 & 16.6 \\
Osiele & 5 & 15.6 & 18 & \\
Total & 32 & & &
\end{tabular}

Table 5. Multiple antimicrobial resistance indices (MARI) of antimicrobials used in live bird markets Abeokuta Ogun state.

\begin{tabular}{ccccc}
\hline S/N & Sample Code & $\begin{array}{c}\text { Live Bird } \\
\text { Market }\end{array}$ & $\begin{array}{c}\text { Antimicrobial } \\
\text { Class }\end{array}$ & MARI \\
\hline 1 & KT 1AE(4) & Kuto & CL,2,3,4,5 & 0.5 \\
2 & ASEJ 3AE(4) & Asejere & CL,3,4,5,6 & 0.3 \\
3 & IT 7AE(4) & Itoku & CL,3,4,5,6 & 0.3 \\
4 & A1AE(3) & Ago Ika & CL,3,5,6 & 0.2 \\
5 & OS 3AE(3) & Osiele & CL,4,5,6 & 0.2 \\
6 & IT 6AE(3) & Itoku & CL,4,5,6 & 0.2 \\
7 & GB 2AE(4) & Gbonagun & CL,3,4,5,6 & 0.3 \\
8 & IT 8AE(3) & Itoku & CL,3,4,5 & 0.2 \\
9 & IT 3AE(3) & Itoku & CL,3,5,6 & 0.2 \\
10 & A 3AE(3) & Ago Ika & CL,3,4,5 & 0.2 \\
11 & IT 5AE(4) & Itoku & CL,3,4,5,6 & 0.3 \\
12 & OS 2AE(4) & Osiele & CL,3,4,5,6 & 0.3 \\
13 & AS 3AE(4) & Asero & CL,3,4,5,6 & 0.3 \\
14 & IT 4AE(4) & Itoku & CL,3,4,5,6 & 0.3 \\
15 & OS 5AE(4) & Osiele & CL,3,4,5,6 & 0.3 \\
16 & AS 1AE(3) & Asero & CL,4,5,6 & 0.2 \\
17 & KT 2AE(4) & Kuto & CL,3,4,5,6 & 0.2 \\
18 & ASEJ 2AE(4) & Asejere & CL,3,4,5,6 & 0.3 \\
\hline
\end{tabular}

Class 1, Beta lactams cephalosporins (ceftriaxone, cefixime, cefuroxime, ceftazidime, cefotaxime); Class 2, fluoroquinolones (ciprofloxacin, ofloxacin, levofloxacin, nalidixic acid); Class 3, nitrofurans (nitrofurantoin); Class 4, beta lactamase inhibitor (amoxicillin clavulanate); Class 5, carbanapems (imipenem); Class 6, aminoglycosides (gentamicin). Classification was carried out based on the motor discs available for antimicrobial susceptibility testing.

Overall, extremely high rates of resistance were reported for ceftazidime $(90.8 \%)$ and imipenem $(90.6 \%)$. In contrast, the isolates had low rates of resistance to ceftriaxone $(9.4 \%)$ ofloxacin $(9.4 \%)$, and cefixime $(6.3 \%)$. The overall antimicrobial resistance profile of the 32 isolates to $14 \mathrm{AMs}$ is summarized in Figure 6. The distribution of antimicrobial resistance of $E$. coli isolates at the LBM level is presented in Table 6

\section{Factors Associated with MDR Escherichia coli}

The use of AMs for prophylactic purpose was associated with MDR E. coli $(\mathrm{COR}=8.05$; 95\% CI; 1.69-38.13; $p=0.01$ ). The odds of MDR E. coli were eight-fold higher in poultry kept by LBS who used AMs to prevent disease compared to those that did not. In contrast, the use of AMs for treatment of LBs when sick was found to be marginally associated with MDR E. coli and reduced the odds of occurrence (COR $=0.17 ; 95 \%$ CI; $0.03-0.98 ; p=0.067$ ). Table 7 described the factors associated with MDR E. coli. 


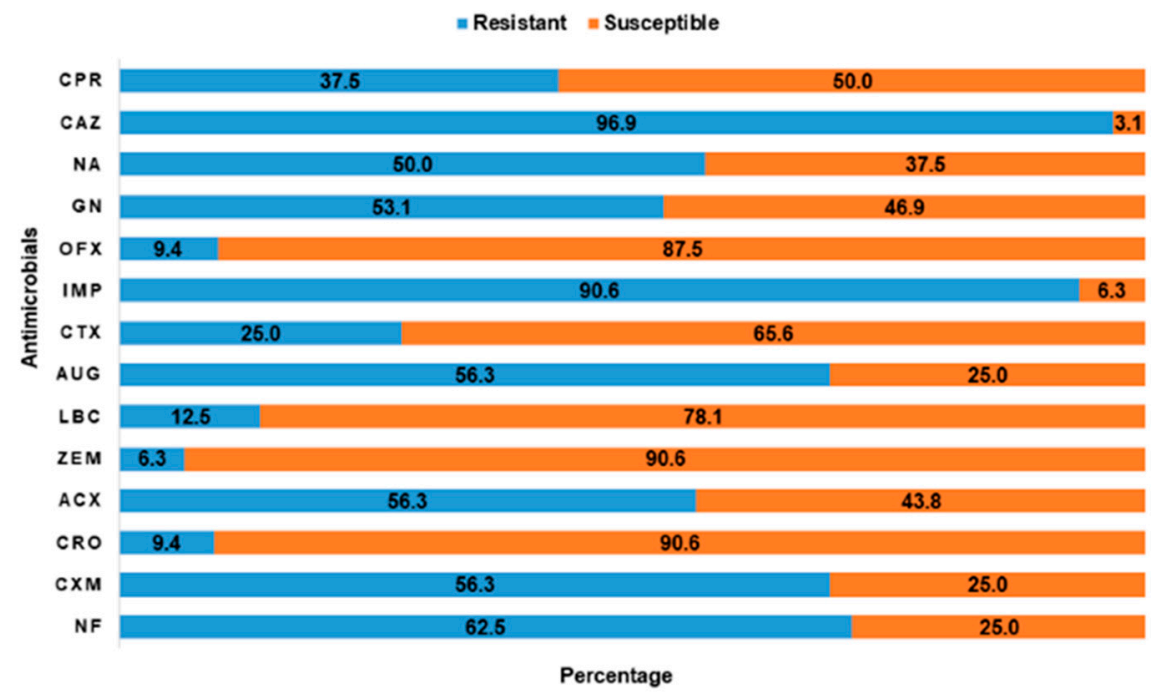

Figure 6. The rates of antimicrobial susceptibility and resistance pattern of putative positive E. coli to 14 antimicrobials tested. ACX, Ampiclox; AUG, Amoxycillin/clavulanic acid; CAZ, Ceftazidime; CPR, Ciprofloxacin; CRO, Ceftriaxone; CTX, Cefotaxime; CXM, Cefuroxime; GN, Gentamicin; IMP, Imipenem; LBC-; NA, Nalidixic acid; NF, Nitrofurantoin; OFX, Ofloxacin; ZEM, Cefexime.

Table 6. The Antimicrobial resistance among E. coli isolates from the eight LBMs in Abeokuta, Ogun State.

\begin{tabular}{|c|c|c|c|c|c|c|c|c|c|c|c|c|c|c|c|}
\hline LBM & $\begin{array}{c}\text { E. coli } \\
(n=32)\end{array}$ & $\begin{array}{l}\text { NF } \\
(\%)\end{array}$ & $\begin{array}{l}\text { CXM } \\
(\%)\end{array}$ & $\begin{array}{l}\text { CRO } \\
(\%)\end{array}$ & $\begin{array}{l}\text { ACXV } \\
(\%)\end{array}$ & $\begin{array}{l}\text { ZEM } \\
(\%)\end{array}$ & $\begin{array}{l}\text { LBC } \\
(\%)\end{array}$ & $\begin{array}{c}\text { AUG } \\
(\%)\end{array}$ & $\begin{array}{l}\text { CTX } \\
(\%)\end{array}$ & $\begin{array}{l}\text { IMP } \\
(\%)\end{array}$ & $\begin{array}{l}\text { OFX } \\
(\%)\end{array}$ & $\begin{array}{l}\text { GN } \\
(\%)\end{array}$ & $\begin{array}{l}\text { NA } \\
(\%)\end{array}$ & $\begin{array}{l}\text { CAZ } \\
(\%)\end{array}$ & $\begin{array}{l}\text { CPR } \\
(\%)\end{array}$ \\
\hline Lafenwa & $n=3$ & 33.3 & 0.0 & 0.0 & 0.0 & 0.0 & 0.0 & 0.0 & 0.0 & 33.3 & 0.0 & 0.0 & 33.3 & 66.7 & 0.0 \\
\hline Kuto & $n=4$ & 50.0 & 50.0 & 0.0 & 75.0 & 0.0 & 50.0 & 50.0 & 0.0 & 100.0 & 50.0 & 25.0 & 100.0 & 100.0 & 75.0 \\
\hline Itoku & $n=9$ & 77.7 & 44.4 & 11.1 & 55.5 & 0.0 & 22.2 & 66.6 & 11.1 & 100.0 & 0.0 & 55.5 & 44.4 & 100.0 & 33.3 \\
\hline Gbonagun & $n=1$ & 100.0 & 100.0 & 100.0 & 100.0 & 0.0 & 0.0 & 100.0 & 0.0 & 100.0 & 0.0 & 100.0 & 100.0 & 100.0 & 100.0 \\
\hline Ago ika & $n=3$ & 66.6 & 33.3 & 0.0 & 66.6 & 0.0 & 0.0 & 33.3 & 66.6 & 100.0 & 33.3 & 33.3 & 33.3 & 100.0 & 33.3 \\
\hline Asero & $n=4$ & 50.0 & 25.0 & 0.0 & 25.0 & 100.0 & 0.0 & 75.0 & 0.0 & 75.0 & 0.0 & 75.0 & 75.0 & 100.0 & 50.0 \\
\hline Asejere & $n=3$ & 100.0 & 100.0 & 33.3 & 66.6 & 33.3 & 0.0 & 66.6 & 33.3 & 100.0 & 0.0 & 66.6 & 33.3 & 100.0 & 33.3 \\
\hline Osiele & $n=5$ & 40.0 & 100.0 & 0.0 & 80.0 & 20.0 & 0.0 & 60.0 & 60.0 & 100.0 & 0.0 & 80.0 & 20.0 & 100.0 & 20.0 \\
\hline
\end{tabular}

ACX, Ampiclox; AUG, Amoxycillin/clavulanic acid; CAZ, Ceftazidime; CPR, Ciprofloxacin; CRO, Ceftriaxone CTX, Cefotaxime; CXM, Cefuroxime; GN, Gentamicin; IMP, Imipenem; LBC-; NA, Nalidixic acid; NF, Nitrofurantoin; OFX, Ofloxacin; ZEM, Cefexime. Table S2. Antimicrobial profile of the positive E. coli isolates from live birds, Abeokuta Ogun State.

Table 7. Bivariate analysis of risk factors associated with MDR E. coli isolates collected from LBMs in Abeokuta, Ogun State.

\begin{tabular}{|c|c|c|c|c|c|c|c|}
\hline \multirow[t]{2}{*}{ Variables } & \multicolumn{7}{|c|}{ MDR E. coli } \\
\hline & Present & $\%$ & Absent & $\%$ & COR & $95 \% \mathrm{CI}$ & $p$ Value \\
\hline \multicolumn{8}{|c|}{ Use human AMs capsules for your birds } \\
\hline Yes & 15 & 78.9 & 12 & 80.0 & 0.94 & $0.17-5.02$ & $0.64^{\mathrm{b}}$ \\
\hline No & 4 & 21.1 & 3 & 20.0 & & & \\
\hline \multicolumn{8}{|c|}{ AMU for treatment of sick poultry } \\
\hline Yes & 11 & 55.0 & 14 & 87.5 & 0.17 & $0.03-0.98$ & $0.06^{\mathrm{b}}$ \\
\hline No & 9 & 45.0 & 1 & $12.5 \%$ & & & \\
\hline \multicolumn{8}{|c|}{ AMU for prophylaxis } \\
\hline Yes & 13 & 65.0 & 12 & 81.3 & 8.04 & $1.69-38.13$ & $0.01^{\mathrm{a} *}$ \\
\hline No & 7 & 35.0 & 3 & 18.7 & & & \\
\hline
\end{tabular}


Table 7. Cont.

\begin{tabular}{|c|c|c|c|c|c|c|c|}
\hline \multirow[t]{2}{*}{ Variables } & \multicolumn{7}{|c|}{ MDR E. coli } \\
\hline & Present & $\%$ & Absent & $\%$ & COR & $95 \%$ CI & $p$ Value \\
\hline \multicolumn{8}{|c|}{ Veterinary Prescription } \\
\hline Yes & 2 & 10.0 & 1 & 6.3 & 1.66 & $0.137-20.23$ & $1.00^{\mathrm{b}}$ \\
\hline No & 18 & 90.02 & 15 & 93.7 & & & \\
\hline \multicolumn{8}{|c|}{ Self-Prescription } \\
\hline Yes & 17 & 85.0 & 15 & $93.7 \%$ & 0.38 & $0.03-4.03$ & $1.00^{\mathrm{b}}$ \\
\hline No & 3 & 15.0 & 1 & 6.3 & & & \\
\hline \multicolumn{8}{|c|}{ Having contact with Vet } \\
\hline Yes & 14 & 63.6 & 9 & 52.9 & 1.56 & $0.43-5.64$ & $0.50^{a}$ \\
\hline No & 8 & 36.4 & 8 & 47.1 & & & \\
\hline \multicolumn{8}{|c|}{ Mix Poultry of various age } \\
\hline Yes & 8 & 35.4 & 11 & 61.1 & 0.36 & $0.10-1.32$ & $0.12^{\mathrm{a}}$ \\
\hline No & 14 & 63.6 & 7 & 38.9 & & & \\
\hline \multicolumn{8}{|c|}{ Mix Poultry of various types } \\
\hline Yes & 14 & 63.6 & 11 & 61.1 & 1.11 & $0.31-4.03$ & $1.00^{\mathrm{a}}$ \\
\hline No & 8 & 36.4 & 7 & 38.9 & & & \\
\hline \multicolumn{8}{|c|}{ Source poultry from various LBS } \\
\hline Yes & 12 & 57.1 & 10 & 55.6 & 1.07 & $0.30-3.79$ & $1.00^{\mathrm{a}}$ \\
\hline No & 9 & 42.9 & 8 & 44.4 & & & \\
\hline \multicolumn{8}{|c|}{ Source poultry from various farms } \\
\hline Yes & 20 & 90.9 & 17 & 94.4 & 0.58 & $0.05-7.07$ & $1.00^{b}$ \\
\hline No & 2 & 9.1 & 1 & 5.6 & & & \\
\hline \multicolumn{8}{|c|}{ Presence of fence } \\
\hline Yes & 2 & 9.5 & 2 & 11.8 & 0.79 & $0.10-6.28$ & $1.00^{b}$ \\
\hline No & 19 & 90.5 & 15 & 88.2 & & & \\
\hline \multicolumn{8}{|c|}{ Presence of Wild birds } \\
\hline Yes & 9 & 40.9 & 8 & 44.4 & 1.16 & $0.33-4.07$ & $0.82^{\mathrm{a}}$ \\
\hline No & 13 & 59.1 & 10 & 55.6 & & & \\
\hline \multicolumn{8}{|c|}{ Health Inspection } \\
\hline Yes & 4 & 18.2 & 4 & 22.2 & 0.79 & $0.16-3.67$ & $1.00^{b}$ \\
\hline No & 18 & 81.8 & 14 & 77.8 & & & \\
\hline \multicolumn{8}{|c|}{ Introduction of poultry without quarantine } \\
\hline Yes & 17 & 89.5 & 14 & $82.4 \%$ & 1.82 & $0.26-12.47$ & $0.65^{b}$ \\
\hline No & 2 & 10.5 & 3 & 17.6 & & & \\
\hline \multicolumn{8}{|c|}{ Presence of sick poultry } \\
\hline Yes & 8 & 36.4 & 9 & 50.0 & 2.17 & $0.57-8.19$ & $0.25^{a}$ \\
\hline No & 14 & 63.6 & 9 & 50.0 & & & \\
\hline \multicolumn{8}{|c|}{ Cage Type } \\
\hline Metal & 10 & 45.5 & 12 & 66.7 & 0.42 & $0.12-1.51$ & $0.18^{a}$ \\
\hline Non-metal & 12 & 55.5 & 6 & 33.3 & & & \\
\hline
\end{tabular}

* Significant at $p \leq 0.05 ;{ }^{\mathrm{a}}=$ Pearson's Chi Square; ${ }^{\mathrm{b}}=$ Fischer's exact test; COR, Crude's odds ratio; CI, confidence interval. 


\subsection{Feedback Meeting, LBS Perceptions towards AMU and AMR, and Challenges}

A feedback meeting was organized with the live bird sellers who participated in the study. The meeting was conducted on the 18th October 2021 and a total of 12 LBS comprising of ten females and two males were in attendance. None of the LBS have had antimicrobial stewardship or poultry management training. Furthermore, the LBS shared their perceptions on antimicrobial use, resistance, and challenges experienced as live bird vendors.

When asked about their perceptions on the indiscriminate use of antimicrobials, one of the LBS responded "We don't use antibiotics to that extent because we purchase matured chickens, which are sold or slaughtered within a few weeks. Antimicrobial abuse is mostly from the poultry farmers because they are the ones involved in the rearing process". Furthermore, the respondents were unaware of the associated AMR implication in humans, but know it was critical not to slaughter chickens placed on antimicrobial treatment.

We also inquired if they observed the antimicrobial withdrawal period, one LBS responded "Yes we do". Another response provided was this "if my chickens are sick, what I do is to isolate and treat them with antibiotics. If I observe no improvement within $24 \mathrm{~h}$ and not to lose money, I slaughter them for my customers (consumers)". In Nigeria, livestock farmers use antimicrobials, but there is little compliance to withdrawal periods due to perceived economic losses. Whether LBS observe withdrawal period or not before slaughtering of chickens for human consumption will need further observational investigations.

Some of the challenges encountered within the business were also discussed. The LBS raised concerns about the lack of prompt response of veterinary services delivery and based this on the main excuse for not consulting veterinarians whenever chickens become sick. Instead, sick chickens are isolated, and treated with human capsules or turn to other sources for treatment guidance which may be unreliable, especially from poultry farmers where chickens were sourced from. The apparently healthy ones are placed on prophylactic treatment to control the spread of disease. "We don't seek for veterinary services when chickens are sick because of the slow response we get from them, but we call them only to fumigate the market premises". Lack of access to veterinary services is a common subject consistently raised as a concern among livestock producers in the country, and one of the perceived reasons for antimicrobial misuse [1,26-28]. Although AMU in animals for prophylaxis and metaphylaxis may have been substantially reduced in high-income countries, it is still a challenge in developing countries.

Lastly, the respondents decried the presence of unregistered live bird sellers bringing various chickens from unknown locations to the open markets especially during the festive periods consequently sabotaging the profits of the registered ones. "We want the government to stop unregistered live bird sellers from sabotaging our efforts and bringing in diseases to our chickens. Only registered LBS should be permitted to sell chickens". LBS further suggested that for progress in the live bird market in the state, the government needs to fund the business, upgrade or modernize the markets to internationally acceptable standards with the provision of guidelines for good biosecurity, adequate processing facilities, basic amenities such as electricity, potable running water, drainages, good and accessible roads, which are all currently lacking. They also requested veterinary services should be prompt, accessible and affordable.

\section{Discussion}

Live bird markets (LBMs) are critical points for surveillance of indiscriminate use of AMs and MDR pathogens of public health importance. They (LBMs) serve as sources of AMR propagation to consumers of LBs, especially since many families in Nigeria depend on poultry products, which are purchased freshly slaughtered or live as a source of protein $[29,30]$. It is thus crucial to consider LBMs as surveillance points for the assessment of biosecurity, AMU, AMR. The knowledge derived therefore should assist in developing empirical and specific mitigation measures and effective antimicrobial stewardship program 
in the poultry industry, including the development of management guidelines for livestock farmers in Nigeria.

The biosecurity and practices of AMU among the LBS surveyed were generally poor. This data supported a preliminary study [1], which reported that majority of LBS had poor biosecurity and AMU in Abeokuta, Ogun State. As with the previous study [1], the presence of wild migratory birds around the live chickens bridges biosecurity and poses a risk to human and animal health and food safety. Wild migratory birds may transmit antimicrobial resistant strains to waterways, food animals, and the environment via possible interaction and fecal contamination [31]. When AMR bacteria colonize wild animals, and especially migratory birds, they become a reservoir and vectors that disperse these bacteria and AMR genes to new localities [31]. Wild migratory birds have been implicated in the introduction, maintenance, and global dissemination of different pathogens of transboundary animal diseases and zoonoses such as Highly Pathogenic Avian Influenza (HPAI), Newcastle disease, and AMR-bacteria such as MDR E. coli [32-38].

Operable biosecurity standards within the livestock industry in Nigeria is still a constraint against the effective control of animal diseases. Poor biosecurity measures and animal health management may result in farmers' overdependence on AMs as a disease prevention strategy $[13,30]$. It is suggested based on this study that there is the need for stakeholders in the food animal industry to have a framework that will identify, prioritize, develop, implement, and enforce guidelines for the best practices for managing live animal farms and markets. Such guidelines or vademecum of the best practices for livestock owners may promote the responsible use of AMs in the study area. The only factor found to contribute to poor biosecurity was the age of live bird sellers, which suggests that there may be the need to intensify targeted educational intervention on the best farm practices and biosecurity especially among LBS below the middle-aged category (this constituted the majority of LBS) in the studied area. Improving literacy on biosecurity and developing and enforcing poultry management standards in LBMs may be critical in reducing indiscriminate use of AMU. However, more scientific data may be needed to promote the best farm practices and the adoption of a set of attitudes and behaviors along the poultry value chain to reduce risks in all activities of the poultry production and marketing systems [39].

Self-medication of sick poultry with common antimicrobials such as tetracycline, chloramphenicol metronidazole, and furazolidone by LBS was reported. It should be noted that such antimicrobials may be purchased from both regular and veterinary pharmacies. In addition, anecdotal evidence revealed that humans may sometimes not complete the dosages of their antimicrobial treatment and the unfinished human antimicrobials may be used to treat animals. These individuals often rely on previous experience without resulting to a proper diagnosis in a veterinary laboratory, and the accompanying antimicrobial sensitivity testing, with consequences on engendering and promoting resistant pathogens. Live bird vendors patronizing regular pharmacy stores and using antibiotics intended for human use in poultry may have detrimental effect on the effectiveness of antibiotics that are important for human medicine and the risk of selecting for drug-resistant bacteria that may spread to poultry consumers. Furthermore, previous reports have raised concerns about the administrations of AMs without veterinarian's prescriptions and livestock farmers over reliance on previous experiences to treat animals. This is a common practice by livestock owners in Nigeria, who often inadvertently understudy and repeat past treatment administered by the veterinarians/para-veterinarians [13,27,40-42]. In addition, the use of banned drugs with known genotoxic and carcinogenic effects on humans for food animal production in the country is worrisome and there is the need for this to be reviewed by the National Agency for Food and Drug Administration and Control (NAFDAC) and the other veterinary governing bodies in Nigeria. Based on these findings, it is crucial to develop and enforce strictly national AMU and AMR policies through one health intervention to enhance prudent use of antimicrobials in both human and animal medicine and AMR containment. Furthermore, exclusive collaboration among the Federal Ministry of Health, 
Ministry of Agriculture and Rural Development, and Ministry of Environment is needed to promote AMR policy and plans towards improving awareness and understanding of AMR through effective risk communication, education and training of stakeholders and the populace.

On antimicrobial resistance (AMR), the World Health Organization recognizes this as a major international health threat [43]. A global projection predicts that the increase of deaths linked to AMR may rise to 10 million deaths in 2050, while 100 trillion USD could be lost [44]. Though the poultry sector is an important source of nutrition, food security, and financial income, it is still faced with the challenges of poor disease control and biosecurity, indiscriminate use of AMs and AMR [45]. The issues of misuse and overuse of AMs and AMR are especially significant in developing countries such as Nigeria, where multiple antimicrobials are not only used to treat infections but prophylactically and as growth promoters [45]. To support this, the MARI estimated in this study indicated MDR E coli isolates originated from high-risk source of contamination where various antimicrobials were used $[46,47]$.

The importance of infections due to multidrug-resistant (MDR) E. coli has been increasingly recognized in recent years and they are associated with increased morbidity and mortality [48]. E. coli also represents a major reservoir of resistance genes that may be responsible for treatment failures in both human and veterinary medicine [8]. According to the World Health Organization [49], resistant Gram-negative bacteria (especially E. coli) have become a major and rapidly increasing problem globally. Presently, there are no new classes of antimicrobials in the pipeline, and so it is unlikely that any new classes of effective antimicrobials will be available for 10 years or more to treat infections caused by resistant Gram-negative bacteria [45]. MDR E. coli in food animals in Nigeria is becoming prevalent $[50,51]$, and several papers have documented MDR E. coli in poultry and poultry products in the country [29,52-54]. The potential risk of spread of MDR to humans through poultry consumption has been established in a case control study conducted in Canada [55]. Another study from Ghana demonstrated that four human isolates and broiler isolates were closely related suggesting a possibility of spread of resistance between the two populations [56]. In Nigeria, a study published in 2019 demonstrated that occupational exposure to poultry on farms and the live bird market environment for over 10 years was associated with acquiring MDR E. coli in humans [5]. On a global scale, E. coli is the most important human pathogen and causes substantially many more infections than Salmonella and Campylobacter combined [49]. Thus, the importance of resistance in E. coli, typically considered a benign commensal, should not be underestimated [49].

Lastly, the resistant pattern of E. coli from this study was observed to be consistent with those reported in poultry farms in Abeokuta by a previous author [52]. Nearly all of the isolates were resistant to ceftazidime and imipenem and suggested the presence of potential extended spectrum beta-lactamase (ESBL) and carbapenemases producing E. coli. There may be a need for further molecular studies to establish this hypothesis. Extremely high rates of resistance to ceftazidime (third generation cephalosporin) and imipenem (carbapenem) by E. coli isolates in this study is worrying since this is an emerging concern in veterinary medicine as these drugs are listed by the $\mathrm{WHO}$ as critically important for human medicine $[57,58]$. Antimicrobials such as extended-spectrum cephalosporins (ESC) and carbapenems have been categorized by the World Health Organization (WHO) as a last resort and critically important antimicrobials (CIAs), with limited alternatives in the cases of resistance development. The WHO has also identified these pathogens as crucial for further research and development of new antibiotics, for instance, carbapenem-resistant enterobacteriales [59]. Similarly, the Centre for Disease Control (CDC) had recommended that care facilities should establish a protocol, in conjunction with Clinical and Laboratory Standard Institute (CLSI) guidelines, to detect resistance and carbapenemase production in Enterobacteriales particularly Klebsiella spp and E. coli and immediately alert epidemiology and infection staff members if identified [60,61]. Carbapenems, such as imipenem and meropenem, are antibiotics with a broad spectrum of activity compared to other $\beta$-lactam 
classes and reserved for known or suspected severe multidrug resistant bacterial infections. Although carbapenem resistance is mediated by a variety of mechanisms and its scope and transmission in livestock and to humans and in either direction is rarely performed or reported $[19,62,63]$.

\section{Materials and Methods}

\subsection{Study Area and Study Population}

The study was conducted in Abeokuta, capital of Ogun State, in the South-West region of Nigeria. Eight LBMs within Abeokuta were included: Gbonagun, Kuto, Lafenwa, Itoku, Ago-ika, Asero, Osiele, and Asejere (Figure 7).
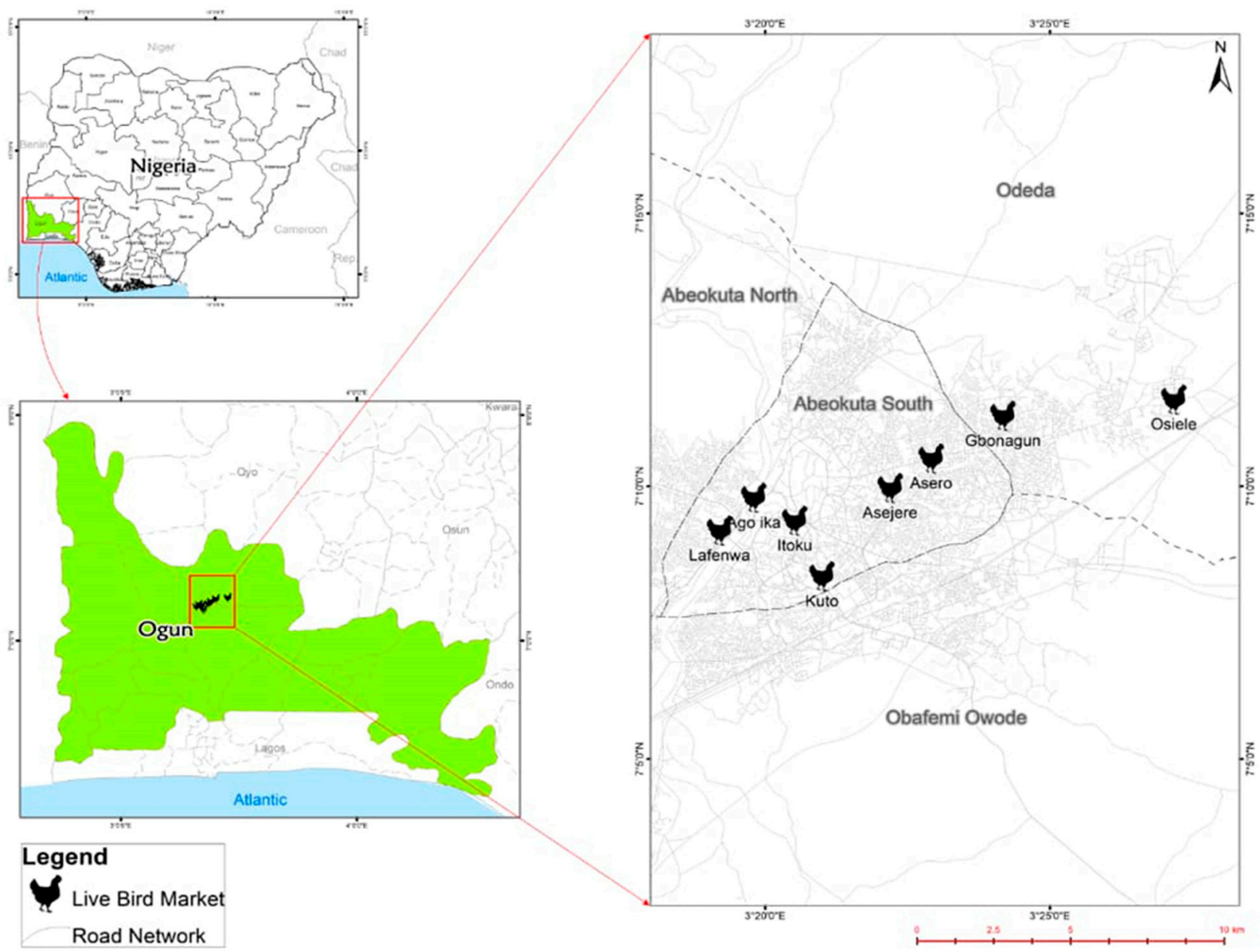

Figure 7. Spatial distribution of LBMs surveyed in Abeokuta, Ogun State.

\subsection{Study Design and Sample Size Estimation}

A cross-sectional study of the eight LBMs within Abeokuta city was conducted from March till August 2021. The target populations were the entire LBMs and LBS in the Abeokuta metropolis. The live bird markets were purposively recruited from the list of LBMs provided by the Department of Livestock, Ministry of Agriculture, Ogun State, Nigeria. All LBMs from the list of registered markets (five) within Abeokuta metropolis were recruited. Three unregistered LBMs were also included to ensure all LBMs within Abeokuta metropolis were captured.

The adjusted sample size of LBS was estimated using WinEpi. The following parameters of $5 \%$ accepted level of precision, expected prevalence of $50 \%$, known population of LBS (100) at 95\% CI were imputed to give an estimated size of 80 LBS. To detect pathogen (MDR E. coli) at an expected minimum prevalence of $65 \%$ at $5 \%$ precision and $95 \%$ con- 
fidence interval (assuming a population ranging between 50-100 chickens per LBS and adopting simple random sampling), a minimum of five chickens were randomly sampled from each participating LBS.

\subsection{The Recruitment of Live Bird Markets (LBM) and Live Bird Sellers (LBS)}

Pre-study visits were made to the Poultry Farmers Association, Ogun State and the live bird market (LBM) coordinators. Signed consent forms were obtained from the two parties. From each participating LBS, informed consent was obtained verbally and witnessed by the LBM coordinator. All respondents in the study were given detailed information about the aims and benefits of the study. Participation in the study was voluntary, and as many as were willing to participate were recruited. Personal identifiers were not collected and each participant's information was treated with confidentiality. Every participant was notified of his/her right to discontinue participation at any stage of the study according to the World Medical Association Declaration of Helsinki, 2001.

\subsection{Questionnaire Design and Data Collection}

The questionnaire used for this survey is a modified version from studies conducted by Adebowale et al., 2016 and Aworh et al., 2019 [5,12]. Permission to modify survey tool was requested and granted by Dr. (Mrs) Mabel Aworh-Ajumobi, an assistant Director/Epidemiologist, Veterinary Drugs Monitoring/Animal Welfare Branch, Quality Assurance and Standards Division, Department of Veterinary and Pests Control Services, Federal Ministry of Agriculture and Rural Development, Abuja, Nigeria. The questionnaire used in this survey was divided into four sections. The information gathered included general data on the LBM, sample flock and biosecurity, live bird seller's demographics, antimicrobial use and resistance, and preferred information channel on antimicrobial stewardship/use and biosecurity. Supplementary File S1 provides further details on the questionnaire. The standardized semi-structured questionnaire was pretested among 10 LBS (who were excluded from the study) and later administered to consenting LBS.

\subsection{Sample Collection}

In total, 200 cloacal samples were obtained from live chickens of consenting LBS (40), which were later pooled. Briefly, five chickens were randomly selected from each cage and sterile cloacal swab samples were taken, packed individually, and transported on ice packs to the laboratory of the Department of Veterinary Microbiology, College of Veterinary Medicine, Federal University of Agriculture Abeokuta, Ogun State within 2-4 h after sampling. All microbiological investigations were conducted in this laboratory.

\subsection{Laboratory Isolation and Identification}

\subsubsection{Non-selective and Selective Enrichment of Samples}

Swabs were broken into tubes containing $2 \mathrm{~mL}$ Buffered Peptone Water (BPW, Oxoid, Basingstoke, United Kingdom), vortexed for $2 \mathrm{~min}$, and later incubated for $24 \mathrm{~h}$ at $37^{\circ} \mathrm{C}$. A loop-full of the bacteria suspension was streaked on MacConkey Agar (MA, Oxoid, Basingstoke, United Kingdom) plates and incubated at $37^{\circ} \mathrm{C}$ for $24 \mathrm{~h}$. Putative positive E. coli colonies usually pink to red were identified, selected randomly, then sub-cultured on Nutrient Agar (NA, Oxoid, Basingstoke, United Kingdom) plates and incubated at $37^{\circ} \mathrm{C}$ for $24 \mathrm{~h}$ under aerobic conditions for the isolation of pure isolates.

\subsubsection{Biochemical Identification of E. coli Isolates}

The putative positive E. coli colonies were streaked on nutrient agar plates for biochemical confirmation. Conventional biochemical tests such as Gram staining, catalase, oxidase, indole, citrate, motility, triple sugar iron were performed for further phenotypic screening of selected pure E. coli colonies as described previously [64]. 


\subsubsection{Antimicrobial Susceptibility Profiling}

The antibiotic susceptibility patterns of E. coli isolates were tested using the Kirby Bauer disk diffusion method and according to the Clinical and Laboratory Standards Institute guidelines [65]. All putative positive isolates were tested using a panel of 14 antimicrobials (Celtech Diagnostics, Belgium) of 6 different classes commonly used in the treatments of human and animal bacterial infections (Table 8). Briefly, one colony of the test isolates from overnight cultures grown on Eosin-Methylene Blue (EMB, Oxoid, Basingstoke, United Kingdom) agar plates were sub cultured onto NA plates for $24 \mathrm{~h}$ at 37 ${ }^{\circ} \mathrm{C}$. Subsequently, Colonies E. coli were emulsified into sterile saline to achieve turbidity equivalent to $0.5 \mathrm{McF}$ arland standard, which is equivalent to $10^{8} \mathrm{CFU} / \mathrm{mL}$. Suspensions were spread using sterile cotton swabs onto Mueller Hinton $(\mathrm{MH})$ agar plates (Oxoid, Basingstoke, United Kingdom), allowed for 5 min to dry, and the antibiotic discs (Table 8) were aseptically placed onto the surface of the $\mathrm{MH}$ agar using sterile forceps, and incubated at $37^{\circ} \mathrm{C}$ for $24 \mathrm{~h}$.

Table 8. The antimicrobials and concentrations of discs for susceptibility assay for E. coli.

\begin{tabular}{|c|c|c|}
\hline Name of Antimicrobials & Class & Concentration Per Disc $(\mu \mathrm{g})$ \\
\hline Ceftriaxone & \multirow{5}{*}{ Cephalosporins } & 10 \\
\hline Cefixime & & 5 \\
\hline Cefuroxime & & 30 \\
\hline Ceftazidime & & 30 \\
\hline Cefotaxime & & 25 \\
\hline Nalidixic acid & \multirow{4}{*}{ Fluoroquinolones } & 30 \\
\hline Ciprofloxacin & & 5 \\
\hline Ofloxacin & & 5 \\
\hline Levofloxacin & & 5 \\
\hline Nitrofurantoin & Nitrofurans & 300 \\
\hline Amoxicillin clavulanate & $\begin{array}{c}\text { beta-lactam beta-lactamase } \\
\text { inhibitor }\end{array}$ & 30 \\
\hline Imipinem & Carbapenem & 10 \\
\hline Gentamicin & Aminoglycosides & 10 \\
\hline
\end{tabular}

The zones of inhibition (diameters) were measured, recorded, and the values were interpreted using standard recommendations of the Clinical and Laboratory Standards Institute. The concentrations and cut-off limits for antimicrobials used for susceptibility testing and outcomes for E. coli isolates are presented in Supplementary Tables S1 and S2. For the quality control (QC), E. coli ATCC 10536 was used.

A strain was considered "resistant" if resistance was observed to at least one antimicrobial agent tested. Also, an isolate was defined "multi-drug resistant" (MDR) if it displayed resistance to three or more classes of antimicrobials [64].

\subsubsection{Rates of Antimicrobial Resistance (AMR)}

To calculate the rate of resistant isolates per 100 for each antimicrobial, we performed the following calculation

$$
\% \text { rate }=\frac{\text { Number of resistant isolates } * 100}{\text { Number of tested isolates }}
$$

According to Papadopoulos et al (2021), resistance \% rates were categorized as extremely high ( $\%$ rate $>70 \%$ ), very high ( $\%$ rate: $>50$ to 70 ), high ( $\%$ rate $>20$ to 50 ), moderate ( $\%$ rate $>10$ to 20$)$, low (\% rate $>1$ to 10$)$, very low (\% rate 0.1 to 1$)$, and rare $(\%$ rate $<0.1)$ [66]. 


\subsubsection{Multiple Antimicrobial Resistance Indices (MARI)}

The multidrug resistance level was quantified using the multiple antibiotic resistance indices (MARI) according to the formula described by the previous author [67].

$$
\text { MARI }=a / b
$$

Where $a=$ total number of antibiotics to which an isolate shows resistance and $b=$ total number of antibiotics to which the isolate was exposed.

\subsection{Data Analyses}

Data analyses were performed for all variables and presented in frequencies and proportions / percentages using Microsoft Excel ${ }^{\circledR}$ (2013), GraphPad Prism 9.20, and SPSS version 23.0. Continuous variables such as number of poultry types, distance between cages, age of LBS, number of work hours, AMU, and biosecurity scores were tested for normality using the Shapiro-Wilk test $(>0.05)$, which informed our use of (Mean \pm SD or Median). To evaluate the biosecurity and AMU level of respondents, a numeric pattern of scoring was used by giving a score of " 1 " for the "correct answer" and " 0 " for an "incorrect" or "I don't know". Respondents' biosecurity and AMU total scores were arrived at by summing correct responses, generating a maximum possible score of 25 and 30 respectively.

The biosecurity and AMU scores were converted to percentages. Thereafter, the overall biosecurity and AMU scores among study respondents were re-grouped into two levels using $<50 \%$ (Poor) and $\geq 50 \%$ (Satisfactory) as cut-off points [68]. The normal Q-Q plot, Shapiro-Wilk test, and simple scatter plot were performed to test the normality and linearity of the distributions of biosecurity and AMU scores and Pearson product-moment correlation coefficient was performed to measure the strength and direction of the linear relationship. The relationship between biosecurity and AMU was investigated using a Pearson product-moment correlation coefficient. Preliminary analyses were performed to ensure no violation of assumptions of normality and linearity.

Associations between the socio-demographics of LBS, biosecurity and AMU were determined using bivariate analysis such as Pearson's Chi-Square or Fischer's exact test (where cells have expected count less than 5). Biosecurity and AMU variables associated with MDR E. coli were further investigated. Outcomes were considered significant at $p \leq$ 0.05. Risk estimates at $95 \%$ CI were reported.

\section{Conclusions}

Reducing antimicrobial consumption and misuse in animals and humans is critical to decreasing the threat of AMR in Nigeria. In this study, AMU and biosecurity practices among LBS in Abeokuta, Ogun state were generally poor. The presence of MDR E. coli in LBMs in the study area suggests that the bacterial organism from poultry source can contribute significantly to the horizontal spread of multi-antimicrobial resistant organisms to humans, and calls for close monitoring in food animals and the environment to protect food animal consumers. It is also crucial for the stakeholders in the livestock industry to develop regulations and the efficient implementation of such standard guidelines or protocols to promote best farm practices and appropriate use of antimicrobials in Nigeria. Likewise, an undivided stakeholders' collaboration (among the government, veterinary professionals, livestock farmers and LBS vendors) to tackle the issue of AMR and achieve the responsible use of AMU in the food animal production value chains (through a one health frame work) is much needed. The LBS's two main preferred sources of information, which were radio and seminars, should be explored by local veterinary professionals and extension officers to promote antimicrobial stewardship for livestock owners. Strategies for efficient information dissemination and risk communication must be developed towards change in attitudes and behaviors among livestock farmers and vendors. Furthermore, the establishment of efficient surveillance systems for monitoring AMU and antimicrobial residues along the poultry production chain is very critical for reducing the emergence and 
risk of horizontal transmission of antimicrobial resistance to consumers and the environment. An increase in access to essential veterinary services must be enhanced and may be achieved through a commitment from the government towards capacity building and the training of more veterinarians and para veterinarians nationally.

Several limitations were identified despite being the first to identify and describe risk factors associated with MDR in a live bird market-based setting in Abeokuta, Ogun State. These limitations restrict the external generalization of our findings. The sample size of respondents (LBS) was small, which may be due to the non- probabilistic convenience (voluntary) sampling approach. In addition, it took quite an effort to recruit the live bird vendors that participated in the study. Some of the vendors were enthusiastic about participating while others were skeptical due to the belief that the sample collection process could result in the death of the chickens.

Our future work is to conduct a similar study at the state level and promote participation, representativeness of LBMs, and more conclusive quantitative data that will be generalizable. Similarly, it is important to conduct future studies especially genetic and nation-wide based surveillance, for a detailed understanding of the molecular epidemiology of MDR in live bird markets and the interconnected human population and the environment.

Supplementary Materials: The following are available online at https: / www.mdpi.com/article/10 .3390 /antibiotics11020253/s1. Questionnaire S1: Questionnaire, Table S1: The Concentrations and Cut-Off Limits Used. For antimicrobials susceptibility testing, Table S2: Antimicrobial Profiles of the Positive E. coli Isolates from Live Chickens in Abeokuta Ogun State.

Author Contributions: Conceptualization, O.A. (Oluwawemimo Adebowale); methodology, O.A. (Oluwawemimo Adebowale), M.M., N.B., M.O., A.A., E.K., O.O. and O.F.; software, O.A. (Oluwawemimo Adebowale); validation, F.O.F. and O.A. (Olanike Adeyemo).; formal analysis, O.A. (Oluwawemimo Adebowale); investigation, O.A. (Oluwawemimo Adebowale), M.M., N.B. and E.K.; data curation, O.A. (Oluwawemimo Adebowale); writing-original draft preparation, O.A. (Oluwawemimo Adebowale); writing - review and editing, F.O.F., O.F. and O.A (Olanike Adeyemo).; visualization, O.A. (Oluwawemimo Adebowale); supervision, O.A. (Oluwawemimo Adebowale). All authors have read and agreed to the published version of the manuscript.

Funding: This research received no external funding.

Institutional Review Board Statement: The institutional ethical review and approvals were granted by the College of Veterinary Medicine Research Ethics (CREC), Federal University of Agriculture Abeokuta, Ogun State Nigeria (Reference no FUNAAB/COLVET/CREC/2020/02/01. The study was conducted according to the guidelines of the Declaration of Helsinki.

Informed Consent Statement: Informed consent was obtained from all subjects involved in the study verbally.

Data Availability Statement: Data are contained within the article or Supplementary Material.

Acknowledgments: The authors acknowledge the Ogun State Ministry of Agriculture, Veterinary Services Department and all participating live bird sellers for their support.

Conflicts of Interest: The authors declare no conflict of interest.

\section{References}

1. Adebowale, O.; Makanjuola, M.; Bankole, N.; Olanike, A.; Awoseyi, A.; Awoyomi, O.J. Biosecurity and Antimicrobial Use Practices in Live Bird Markets within Abeokuta Metropolis, Southwest, Nigeria: A Preliminary Survey. Maced. Vet. Rev. 2021, 44, 187-202. [CrossRef]

2. Ogundipe, F.O.; Ojo, O.E.; Feßler, A.T.; Hanke, D.; Awoyomi, O.J.; Ojo, D.A.; Akintokun, A.K.; Schwarz, S.; Maurischat, S. Antimicrobial Resistance and Virulence of Methicillin-Resistant Staphylococcus aureus from Human, Chicken and Environmental Samples within Live Bird Markets in Three Nigerian Cities. Antibiotics 2020, 9, 588. [CrossRef] [PubMed]

3. Cardona, C.; Yee, K.; Carpenter, T. Are live bird markets reservoirs of avian influenza? Poult. Sci. 2009, 88, 856-859. [CrossRef] 
4. Fasanmi, O.G.; Ahmed, S.S.U.; Oladele-Bukola, M.O.; El-Tahawy, A.S.; Elbestawy, A.R.; Fasina, F.O. An evaluation of biosecurity compliance levels and assessment of associated risk factors for highly pathogenic avian influenza H5N1 infection of live-birdmarkets, Nigeria and Egypt. Acta Trop. 2016, 164, 321-328. [CrossRef] [PubMed]

5. Aworh, M.K.; Kwaga, J.; Okolocha, E.; Mba, N.; Thakur, S. Prevalence and risk factors for multi-drug resistant Escherichia coli among poultry workers in the Federal Capital Territory, Abuja, Nigeria. PLoS ONE 2019, 14, e0225379. [CrossRef]

6. Fagbamila, I.; Barco, L.; Mancin, M.; Kwaga, J.; Ngulukun, S.S.; Zavagnin, P.; Lettini, A.A.; Lorenzetto, M.; Abdu, P.A.; Kabir, J.; et al. Salmonella serovars and their distribution in Nigerian commercial chicken layer farms. PLoS ONE 2017, 12, e0173097. [CrossRef] [PubMed]

7. Kabir, S.M.L. Avian Colibacillosis and Salmonellosis: A Closer Look at Epidemiology, Pathogenesis, Diagnosis, Control and Public Health Concerns. Int. J. Environ. Res. Public Health 2010, 7, 89-114. [CrossRef]

8. Poirel, L.; Madec, J.-Y.; Lupo, A.; Schink, A.-K.; Kieffer, N.; Nordmann, P.; Schwarz, S. Antimicrobial Resistance in Escherichia coli. Microbiol. Spectr. 2018, 6, 289-316. [CrossRef]

9. Kaper, J.B.; Nataro, J.P.; Mobley, H.L. Pathogenic Escherichia coli. Nat. Rev. Microbiol. 2004, 2, 123-140. [CrossRef]

10. Chandran, A.; Mazumder, A. Pathogenic potential, genetic diversity, and population structure of Escherichia coli strains isolated from a forest-dominated watershed (Comox Lake) in British Columbia, Canada. J. Appl. Microbiol. 2015, 81, 1788-1798. [CrossRef]

11. Looft, T.; Johnson, T.A.; Allen, H.K.; Bayles, D.O.; Alt, D.P.; Stedtfeld, R.D.; Sul, W.J.; Stedtfeld, T.M. In-feed antibiotic effects on the swine intestinal microbiome. Proc. Natl. Acad. Sci. USA 2012, 109, 1691-1696. [CrossRef]

12. Adebowale, O.O.; Adeyemo, O.K.; Awoyomi, O.; Dada, R.; Adebowale, O. Antibiotic use and practices in commercial poultry laying hens in Ogun State Nigeria. Rev. D'élevage Médecine Vétérinaire Pays Trop. 2016, 69, 41-45. [CrossRef]

13. Joshua, A.; Moses, A.; Akinkunmi, E.O. A Survey of Antimicrobial Agents Usage in Poultry Farms and Antibiotic Resistance in Escherichia Coli and Staphylococci Isolates from the Poultry in Ile-Ife, Nigeria. J. Infect. Dis. Epidemiol. 2018, 4, 47. [CrossRef]

14. Adebowale, O.O.; Ekundayo, O.; Awoseyi, A.A. Female cattle slaughter and foetal wastage: A case study of the Lafenwa abattoir, Ogun state, Nigeria. Cogent Food Agric. 2020, 6, 1809308. [CrossRef]

15. Lawal, J.R.; Jajere, S.M.; Geidam, Y.A.; Bello, A.M.; Wakil, Y.; Mustapha, M. Antibiotic Residues in Edible Poultry Tissues and Products in Nigeria: A Potential Public Health Hazard. Int. J. Anim. Vet. Adv. 2015, 7, 55-61. [CrossRef]

16. Kabir, J.; Umoh, V.; Audu-Okoh, E.; Umoh, J.; Kwaga, J. Veterinary drug use in poultry farms and determination of antimicrobial drug residues in commercial eggs and slaughtered chicken in Kaduna State, Nigeria. Food Control 2004, 15, 99-105. [CrossRef]

17. Jochum, J.M.; Redweik, G.A.J.; Ott, L.C.; Mellata, M. Bacteria Broadly-Resistant to Last Resort Antibiotics Detected in Commercial Chicken Farms. Microorganisms 2021, 9, 141. [CrossRef]

18. Economou, V.; Gousia, P. Agriculture and food animals as a source of antimicrobial-resistant bacteria. Infect. Drug Resist. 2015, 8 , 49-61. [CrossRef]

19. Hegde, N.V.; Kariyawasam, S.; DebRoy, C. Comparison of antimicrobial resistant genes in chicken gut microbiome grown on organic and conventional diet. Vet. Anim. Sci. 2016, 1-2, 9-14. [CrossRef]

20. Subramanya, S.H.; Bairy, I.; Metok, Y.; Baral, B.P.; Gautam, D.; Nayak, N. Detection and characterization of ESBL-producing Enterobacteriaceae from the gut of subsistence farmers, their livestock, and the surrounding environment in rural Nepal. Sci. Rep. 2021, 11, 2091. [CrossRef]

21. Ibrahim, S.; Hoong, L.W.; Siong, Y.L.; Mustapha, Z.; Zalati, C.C.W.; Aklilu, E.; Mohamad, M.; Kamaruzzaman, N. Prevalence of Antimicrobial Resistance (AMR) Salmonella spp. and Escherichia coli Isolated from Broilers in the East Coast of Peninsular Malaysia. Antibiotics 2021, 10, 579. [CrossRef] [PubMed]

22. Ibrahim, A.; Junaidu, A.; Garba, M. Multiple antibiotic residues in meat from slaughtered cattle in Nigeria. Internet J. Vet. Med. 2010, 8, 354

23. Adenipekun, E.O.; Jackson, C.R.; Oluwadun, A.; Iwalokun, B.; Frye, J.; Barrett, J.B.; Hiott, L.M.; Woodley, T.A. Prevalence and Antimicrobial Resistance in Escherichia coli from Food Animals in Lagos, Nigeria. Microb. Drug Resist. 2015, 21, 358-365. [CrossRef] [PubMed]

24. Igwe, J.C.; Olayinka, B.O.; Ehnimidu, J.O.; Onaolapo, J.A. Virulent Characteristics of Multidrug Resistant E. coli from Zaria, Nigeria. Clin. Microbiol. Open Access 2016, 5, 1000268. [CrossRef]

25. Aworh, M.K.; Kwaga, J.K.P.; Hendriksen, R.S.; Okolocha, E.C.; Thakur, S. Genetic relatedness of multidrug resistant Escherichia coli isolated from humans, chickens and poultry environments. Antimicrob. Resist. Infect. Control 2021, 10, 58. [CrossRef] [PubMed]

26. Hosain, Z.; Kabir, S.M.L.; Kamal, M. Antimicrobial uses for livestock production in developing countries. Vet. World 2021, 14, 210-221. [CrossRef]

27. Oloso, N.O.; Fagbo, S.; Garbati, M.; Olonitola, S.O.; Awosanya, E.J.; Aworh, M.K.; Adamu, H.; Odetokun, I.A.; Fasina, F.O. Antimicrobial resistance in food animals and the environment in Nigeria: A Review. Int. J. Environ. Res. Public Health 2018, 15, 1284. [CrossRef]

28. Adeyemo, O.K.; Alarape, S.A.; Adetunji, V.E.; Saka, A.B.; Adebowale, O.O.; Ubiogoro, O.O.; Agbede, S.A. Safety Hazards Along Animal Food Supply Chain in Nigeria. In Food Security and Safety, 1st ed.; Springer: Cham, Switzerland, 2021 ; pp. 869-883.

29. Aworh, M.K.; Kwaga, J.; Okolocha, E.; Harden, L.; Hull, D.; Hendriksen, R.S.; Thakur, S. Extended-spectrum B-lactamaseproducing Escherichia coli among humans, chickens and poultry environments in Abuja, Nigeria. One Health Outlook 2020, 2, 8. [CrossRef] 
30. Jibril, A.H.; Bello, M.B.; Bello, S.M.; Saheed, Y.; Balla, F.M. Biosecurity Measures and Constraints among Rural Poultry Farmers in Zamfara State, Nigeria. Anim. Vet. Sci. 2016, 4, 47-51. [CrossRef]

31. Carroll, D.; Wang, J.; Fanning, S.; McMahon, B.J. Antimicrobial Resistance in Wildlife: Implications for Public Health. Zoonoses Public Health 2015, 62, 534-542. [CrossRef]

32. Hamer, S.A.; Lehrer, E.; Magle, S.B. Wild Birds as Sentinels for Multiple Zoonotic Pathogens Along an Urban to Rural Gradient in Greater Chicago, Illinois. Zoonoses Public Health 2012, 59, 355-364. [CrossRef] [PubMed]

33. Choi, M.J.; Torremorell, M.; Bender, J.; Smith, K.E.; Boxrud, D.; Ertl, J.R.; Yang, M.; Suwannakarn, K.; Her, D.; Nguyen, J.; et al Live Animal Markets in Minnesota: A Potential Source for Emergence of Novel Influenza A Viruses and Interspecies Transmission. Clin. Infect. Dis. 2015, 61, 1355-1362. [CrossRef] [PubMed]

34. Lowenstein, C.; Roess, A.; Leibler, J.H.; Graham, J.P.; Waters, W.F. Animal Husbandry Practices and Perceptions of Zoonotic Infectious Disease Risks among Livestock Keepers in a Rural Parish of Quito, Ecuador. Am. J. Trop. Med. Hyg. 2016, 95, 1450-1458 [CrossRef] [PubMed]

35. Agnew, A.; Wang, J.; Fanning, S.; Bearhop, S.; Mc Mahon, B.J. Insights into antimicrobial resistance among long distance migratory East Canadian High Arctic light-bellied Brent geese (Branta bernicla hrota). Ir. Vet. J. 2015, 69, 13. [CrossRef] [PubMed]

36. Nabil, N.M.; Erfan, A.M.; Tawakol, M.M.; Haggag, N.M.; Naguib, M.M.; Samy, A. Wild Birds in Live Birds Markets: Potential Reservoirs of Enzootic Avian Influenza Viruses and Antimicrobial Resistant Enterobacteriaceae in Northern Egypt. Pathogens 2020, 9, 196. [CrossRef] [PubMed]

37. Ramey, A.M.; Ahlstrom, C.A. Antibiotic resistant bacteria in wildlife: Perspectives on trends, acquisition and dissemination, data gaps, and future directions. J. Wildl. Dis. 2020, 56, 1-15. [CrossRef]

38. Jorquera, C.B.; Moreno-Switt, A.I.; Sallaberry-Pincheira, N.; Munita, J.M.; Navarro, C.F.; Tardone, R.; González-Rocha, G.; Singer R.S.; Bueno, I. Antimicrobial resistance in wildlife and in the built environment in a wildlife rehabilitation center. One Health 2021, 13, 100298. [CrossRef]

39. Mikecz, O.; Pica-Ciamarra, U.; Felis, A.; Nizeyimana, G.; Okello, P.; Brunelli, C. Data on antimicrobial use in livestock: Lessons from Uganda. One Health 2020, 10, 100165. [CrossRef]

40. Adebowale, O.O.; Adeyemo, F.A.; Bankole, N.; Olasoju, M.; Adesokan, H.K.; Fasanmi, O.; Adeyemo, O.; Awoyomi, O.; Kehinde, O.; Fasina, F.O. Farmers' Perceptions and Drivers of Antimicrobial Use and Abuse in Commercial Pig Production, Ogun State, Nigeria. Int. J. Environ. Res. Public Health 2020, 17, 3579. [CrossRef]

41. Adelowo, O.O.; Okunlola, I.O. Field assessment of antibiotic use in fish farms in Southwestern Nigeria. Rev. D'élevage Médecine Vétérinaire Pays Trop. 2019, 72, 187-191. [CrossRef]

42. Geidam, Y.; Ibrahim, U.; Grema, H.; Sanda, K.; Suleiman, A.; Mohzo, D. Patterns of Antibiotic Sales by Drug Stores and Usage in Poultry Farms: A Questionnaire-Based Survey in Maiduguri, Northeastern Nigeria. J. Anim. Vet. Adv. 2012, 11, 2852-2855. [CrossRef]

43. Ortega-Paredes, D.; Barba, P.; Mena-López, S.; Espinel, N.; Crespo-Pérez, V.; Zurita, J. High quantities of multidrug-resistant Escherichia coli are present in the Machángara urban river in Quito, Ecuador. J. Water Health 2020, 18, 67-76. [CrossRef]

44. Ortega-Paredes, D.; de Janon, S.; Villavicencio, F.; Ruales, K.J.; de La Torre, K.; Villacís, J.E.; Wagenaar, J.A.; Matheu, J.; BravoVallejo, C.; Fernández-Moreira, E.; et al. Broiler Farms and Carcasses Are an Important Reservoir of Multi-Drug Resistant Escherichia coli in Ecuador. Front. Vet. Sci. 2020, 7, 1-8. [CrossRef] [PubMed]

45. Ma, F.; Xu, S.; Tang, Z.; Li, Z.; Zhang, L. Use of antimicrobials in food animals and impact of transmission of antimicrobial resistance on humans. Biosaf. Health 2020, 3, 32-38. [CrossRef]

46. Chitanand, M.P.; Kadam, T.A.; Gyananath, G.; Totewad, N.D.; Balhal, D.K. Multiple antibiotic resistance indexing of coliforms to identify high risk contamination sites in aquatic environment. Indian J. Microbiol. 2010, 50, 216-220. [CrossRef] [PubMed]

47. Akpan, S.N.; Odeniyi, O.A.; Adebowale, O.O.; Alarape, S.A.; Adeyemo, O.K. Antibiotic resistance profile of Gram-negative bacteria isolated from Lafenwa abattoir effluent and its receiving water (Ogun River) in Abeokuta, Ogun state, Nigeria. Onderstepoort J. Vet. Res. 2020, 87, a1854. [CrossRef]

48. Rottier, W.C.; Ammerlaan, H.S.M.; Bonten, M.J.M. Effects of confounders and intermediates on the association of bacteraemia caused by extended-spectrum $\beta$-lactamase-producing Enterobacteriaceae and patient outcome: A meta-analysis. J. Antimicrob. Chemother. 2012, 67, 1311-1320. [CrossRef]

49. World Health Organisation; WHO Advisory Group on Integrated Surveillance of Antimicrobial Resistance (AGISAR). Critically Important Antimicrobials for Human Medicine; World Health Organisation: Geneva, Switzerland, 2011; pp. 1-38.

50. Ajayi, A.; Oluyege, A.; Olowe, O.; Famurewa, O. Antibiotic Resistance among Commensal Escherichia coli Isolated from Faeces of Cattle in Ado-Ekiti, Nigeria. J. Anim. Vet. Adv. 2011, 10, 174-179. [CrossRef]

51. Oluduro, A.O. Antibiotic-resistant commensal Escherichia coli in faecal droplets from bats and poultry in Nigeria. Vet. Ital. 2012, 48, 297-308.

52. Ogunleye, A.O.; Oyekunle, M.A.; Sonibare, A.O. Multidrug resistant Escherichia coli isolates of poultry origin in Abeokuta, South Western Nigeria. Vet. Arh. 2008, 78, 501-509.

53. Sharma, P.; Gupta, S.K.; Adenipekun, E.O.; Barrett, J.B.; Hiott, L.M.; Woodley, T.A.; Iwalokun, B.; Oluwadun, A.; Ramadan, H.; Frye, J.G.; et al. Genome Analysis of Multidrug-Resistant Escherichia coli Isolated from Poultry in Nigeria. Foodborne Pathog. Dis. 2020, 17, 1-7. [CrossRef] [PubMed] 
54. Ejikeugwu, C.; Nworie, O.; Saki, M.; Al-Dahmoshi, H.O.M.; Al-Khafaji, N.S.K.; Ezeador, C.; Nwakaeze, E.; Eze, P.; Oni, E.; Obi, C.; et al. Metallo- $\beta$-lactamase and AmpC genes in Escherichia coli, Klebsiella pneumoniae, and Pseudomonas aeruginosa isolates from abattoir and poultry origin in Nigeria. BMC Microbiol. 2021, 21, 124. [CrossRef] [PubMed]

55. Manges, A.R.; Smith, S.P.; Lau, B.J.; Nuval, C.J.; Eisenberg, J.N.S.; Dietrich, P.S.; Riley, L.W. Retail Meat Consumption and the Acquisition of Antimicrobial Resistant Escherichia coli Causing Urinary Tract Infections: A Case-Control Study. Foodborne Pathog. Dis. 2007, 4, 419-431. [CrossRef] [PubMed]

56. Falgenhauer, L.; Imirzalioglu, C.; Oppong, K.; Akenten, C.W.; Hogan, B.; Krumkamp, R.; Poppert, S.; Levermann, V.; Schwengers, O.; Sarpong, N.; et al. Detection and Characterization of ESBL-Producing Escherichia coli from Humans and Poultry in Ghana. Front. Microbiol. 2019, 9, 3358. [CrossRef]

57. Adenipekun, E.O.; Jackson, C.R.; Ramadan, H.; Iwalokun, B.; Oyedeji, K.S.; Frye, J.G.; Barrett, J.B.; Hiott, L.M.; Woodley, T.A.; Oluwadun, A. Prevalence and multidrug resistance of Escherichia coli from community-acquired infections in Lagos, Nigeria. J. Infect. Dev. Ctries. 2016, 10, 920-931. [CrossRef]

58. World Health Organization. Critically Important Antimicrobials for Human Medicine, 6th ed.; World Health Organization: Geneva, Switzerland, 2018; pp. 1-52.

59. Ramsamy, Y.; Mlisana, K.P.; Amoako, D.G.; Abia, A.L.K.; Ismail, A.; Allam, M.; Mbanga, J.; Singh, R.; Essack, S.Y. Mobile genetic elements-mediated Enterobacterales-associated carbapenemase antibiotic resistance genes propagation between the environment and humans: A One Health South African study. Sci. Total Environ. 2022, 806, 150641. [CrossRef]

60. Lledo, W.; Hernandez, M.; Lopez, E.; Molinari, O.L.; Soto, R.Q.; Hernandez, E.; Santiago, N.; Flores, M.; Vazquez, G.J.; Robledo, I.E.; et al. Guidance for Control of Infections with Carbapenem-Resistant or Carbapenemase-Producing Enterobacteriaceae in Acute Care Facilities. Morb. Mortal. Wkly. Rep. 2009, 58, 256-260.

61. Wong, D.; van Duin, D. Novel Beta-Lactamase Inhibitors: Unlocking Their Potential in Therapy. Drugs 2017, 77, 615-628. [CrossRef]

62. Codjoe, F.S.; Donkor, E.S. Carbapenem Resistance: A Review. Med. Sci. 2017, 6, 1. [CrossRef]

63. Köck, R.; Daniels-Haardt, I.; Becker, K.; Mellmann, A.; Friedrich, A.W.; Mevius, D.; Schwarz, S.; Jurke, A. Carbapenem-resistant Enterobacteriaceae in wildlife, food-producing, and companion animals: A systematic review. Clin. Microbiol. Infect. 2018, 24, 1241-1250. [CrossRef]

64. Mgaya, F.; Matee, M.; Muhairwa, A.; Hoza, A. Occurrence of Multidrug Resistant Escherichia coli in Raw Meat and Cloaca Swabs in Poultry Processed in Slaughter Slabs in Dar es Salaam, Tanzania. Antibiotics 2021, 10, 343. [CrossRef] [PubMed]

65. CLSI Supplement M100; Performance Standards for Antimicrobial Susceptibility Testing, 27th ed.; Clinical Laboratory Standards Institute: Wayne, PA, USA, 2013.

66. Papadopoulos, D.; Papadopoulos, T.; Papageorgiou, K.; Sergelidis, D.; Adamopoulou, M.; Kritas, S.K.; Petridou, E. Anti-microbial resistance rates in commensal Escherichia coli isolates from healthy pigs in Greek swine farms. J. Hell. Vet. Med. Soc. 2021, 72, 2909-2916.

67. Krumperman, P.H. Multiple antibiotic resistance indexing of Escherichia coli to identify high-risk sources of fecal contamination of foods. Appl. Environ. Microbiol. 1983, 46, 165-170. [CrossRef] [PubMed]

68. Olasoju, M.I.; Olasoju, T.I.; Adebowale, O.O.; Adetunji, V.O. Knowledge and practice of cattle handlers on antibiotic residues in meat and milk in Kwara State, Northcentral Nigeria. PLoS ONE 2021, 16, e0257249. [CrossRef] 